\title{
Seismic triggering of landslides. Part B: Simulation of dynamic failure processes
}

\author{
H.-B. Havenith ${ }^{1}$, A. Strom ${ }^{2}$, F. Calvetti ${ }^{3}$, and D. Jongmans ${ }^{4}$ \\ ${ }^{1}$ GeomaC-LGIH, University of Liege, B52, 4000 Sart Tilman - Liege, Belgium \\ ${ }^{2}$ Institute of the Dynamics of the Geosphere, Leninsky Avenue, 119334 Moscow, Russia \\ ${ }^{3}$ Dipartimento di Ingegneria Strutturale, Politecnico di Milano, Pzza. Leonardo da Vinci 32, 20133 Milano, Italy \\ ${ }^{4}$ LIRIGM, Université Joseph Fourier Grenoble, BP53, 38041 Grenoble cedex 9, France
}

Received: 12 August 2002 - Revised: 14 January 2003 - Accepted: 16 January 2003

\begin{abstract}
From field observations it is possible to establish correlations between geological conditions and landslide occurrence. However, in general, it is difficult to assess the affect of individual factors on slope instability because of their mutual interaction. In addition, the dynamic effect of propagating seismic waves significantly increases the complexity of the slope stability problem. Wave diffraction, reflection and focusing effects are dependent on local geological conditions and make it difficult to analyse dynamic sliding mechanisms using field observations alone. As a consequence, in order to examine the influence of various geological and seismic factors on slope movements, it is often necessary to produce numerical models. This paper describes the results of such models as applied to two case studies in Kyrgyzstan: the Ananevo rockslide, located in granite, and the Suusamyr debris slump-flow, situated within soft sediments (see Part A: Havenith et al., 2003). Discrete element modelling (UDEC), adapted both to the discontinuous character of fractured rock and to the heterogeneity of layered mediums, was used. This permitted simulation of deformation mechanisms, including seismically induced bending, block tilting, and slip. Particular attention was paid to the interaction between deformation mechanisms, site-specific amplification effects, and subsurface structure.
\end{abstract}

\section{Introduction}

It is often difficult to distinguish between earthquaketriggered landslides and static slope instabilities on the basis of geological environment and geomorphologic features alone. Indeed, both the size and the type of landslides induced under static or seismic conditions are quite similar. On the other hand, it seems that the location of the landslide scarps may provide indications about the origin of the mass movement. Examples cited in Part A (Havenith et al., 2003)

Correspondence to: H.-B. Havenith

(HB.Havenith@ulg.ac.be) reveal a morphological dependency of the seismic slope failure occurrence. They show that seismically triggered slope failures tend to occur in the upper parts of slopes and close to ridge-crests, such as observed after the $M=7.6$ Guatemala earthquake in 1976 (Harp et al., 1981) and the $M=7.3 \mathrm{El}$ Asnam earthquake in 1980 (Durville and Méneroud, 1982). Other studies demonstrate the possible influence of hilltop weathering on the initiation of seismic landslides, as in the case of the Fatalak landslide triggered by the $M=7.3$ Manjil (Iran) earthquake in 1990 (Ishihara et al., 1992).

The present study examines the affect of surface morphology and geological subsurface materials on earthquake ground motions based on field evidence from three landslide sites in the northern Tien Shan (Kyrgyzstan, Central Asia). The data recorded at these sites were described in detail recently (Part A: Havenith et al., 2003). After a brief review of these field observations, this paper (Part B) presents the results of a numerical analysis applied to two of the three investigated slope failures: the Ananevo rockslide and the Suusamyr debris slide.

In general, the computation of seismic instability is based on classical limit-analyses (e.g. with Janbu's method: Janbu, 1973) of the corresponding static problem, to which a seismic load is applied. A well-known method is that developed by Newmark (Newmark, 1965) using an accelerogram as seismic load in order to compute a finite displacement of the slope. However, the application of this technique is limited because it does not take adequate account of the dynamic behaviour of the materials. In the last decade, several analytical procedures have been developed to overcome some of the limits of this method, including the introduction of material compliance (Kramer and Smith, 1997) and post-seismic displacement calculation (Ambraseys and Srbulov, 1995).

Numerical modelling provides an alternative method conceived to compute the real dynamic interaction between material, site geometry and wave propagation. However, in general, Newmark's method remains the preferred approach, probably due to its simplicity. Indeed, only a few applications of numerical modelling to seismic landslides are known 
a)

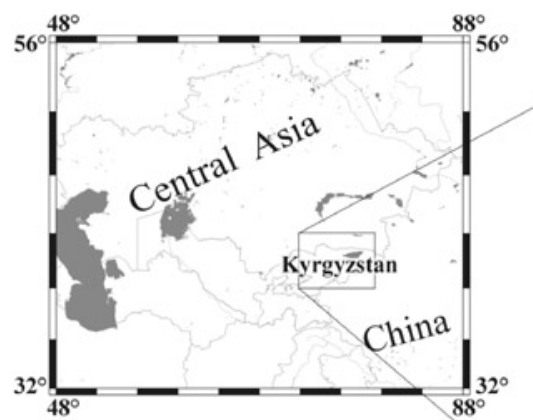

b)

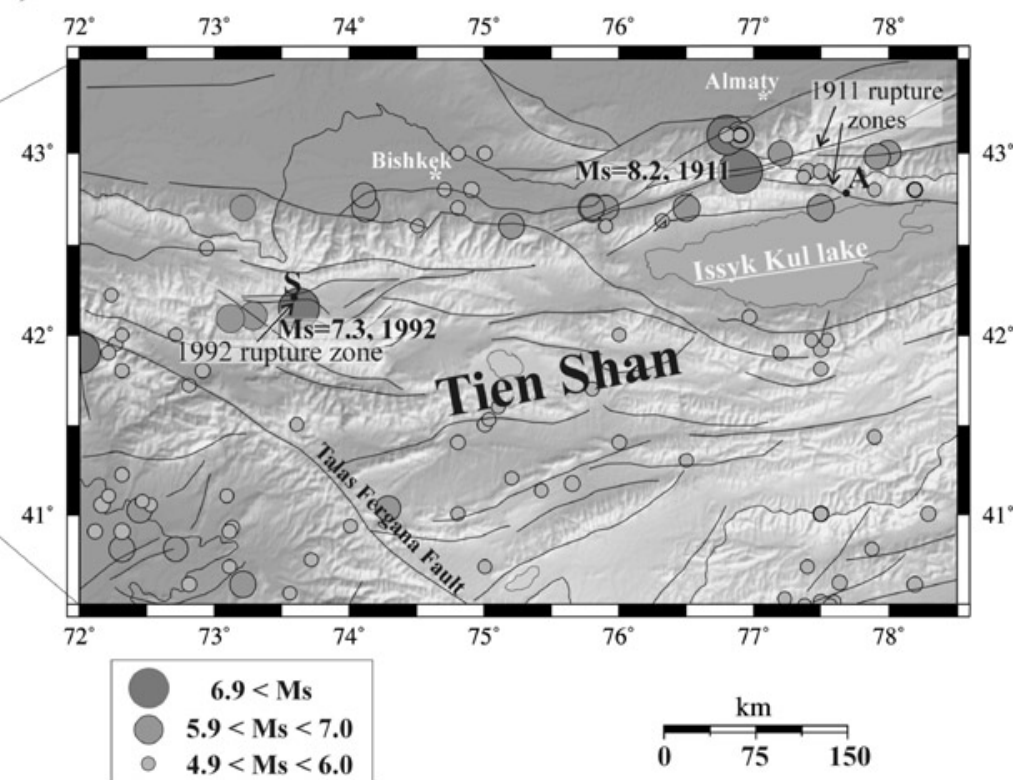

Fig. 1. (a) Location of Kyrgyzstan. (b) Seismo-tectonic map of the Northern and Central Tien Shan showing the traces of major faults close to the investigated sites: Ananevo (A) and Suusamyr (S). Detailed are also earthquakes and related fault ruptures involved in the triggering of the landslides at the first three sites: the $M s=8.2$ Kemin earthquake in 1911 with ruptures zones along the roughly E-W trending Chilik-Kemin strike-slip fault and along the Chon Aksu thrust fault (close to A); the $M s=7.3$ Suusamyr earthquake in 1992 with rupturing of the Aramsu thrust fault.

by the authors (e.g. Ugai et al., 1996). More common are numerical analyses of dynamic slope instabilities triggered by artificial sources, such as explosions or nuclear tests (e.g. Damjanac et al., 1999). Widespread applications exist principally in the domain of static slope stability problems studied numerically by finite element (FEM), spectral element (SEM), finite difference (FDM) or distinct element modelling (DEM; Cundall, 1971). Examples include stability estimation of the Rosone landslide in the western Alps computed with FEM (Forlati et al., 2001); back-analysis of the Frank slide (Canada) with FDM (FLAC) and DEM codes (UDEC) by Benko and Stead (1998); and simulation of the Val Pola (Italy) rock avalanche with DEM (PFC2-D) carried out by Calvetti et al. (2000).

In this study, the UDEC distinct element code was used for the computation of dynamic deformation mechanisms along slopes and ridges. The input parameters of the models were varied in order to assess the sensitivity of the results with regard to the data. The present paper describes a section of the parametric analysis. Its central aim is to detect the morphological, structural and lithological factors influencing seismic stability. The reliability and relevance of the simulations is checked by comparison of the outputs with former results and with the experimental data.

\section{The Ananevo and Suusamyr case-studies}

The Ananevo and Suusamyr sites are located in Kyrgyzstan, in the Northern Tien Shan Mountains (Fig. 1). The Ananevo rockslide north of the lake Issyk Kul was triggered by the
$M s=8.2$ Kemin earthquake in 1911, whereas the Suusamyr debris slide occurred more recently during the $M s=7.3$ Suusamyr earthquake in 1992. During this event, another prominent surface effect, a $100 \mathrm{~m}$ long and $8 \mathrm{~m}$ wide graben, appeared on the Chet Korumdy ridge-crest above the landslide (Fig. 4a).

Both landslide sites were principally investigated by geophysical methods, but also geotechnical tests, fracture and neotectonic analyses as well as trenching work were carried out. In addition, a local seismological network was installed for two months around the Ananevo rockslide (see approximate location of seismological stations around the rockslide in Fig. 2a). Results of the geophysical and seismological surveys are shown in Part A (Havenith et al., 2003). In particular, the latter revealed strong site effects all around the Ananevo rockslide with amplification values higher than 8 between 0.7 and $2 \mathrm{~Hz}$ at the stations close to the mountain crest.

Using the geophysical and geotechnical data, 3-D geological models (Figs. 2c and 4b) of the sites were constructed. From these, 3-D models prior to failure were obtained by extrapolation of present-day contour levels and by using the geophysical information on the depth of the landslide bodies. The models are composed of several material layers characterized by elastic and plastic properties. The Ananevo model further includes a fault zone supposed to represent the Chon Aksu fault (rupture zone close to Ananevo in Fig. 1b) activated in 1911 by the $M s=8.2$ Kemin event. On the basis of cross-sections through the 3-D structure prior to failure, 2-D numerical models were built according to the format required 


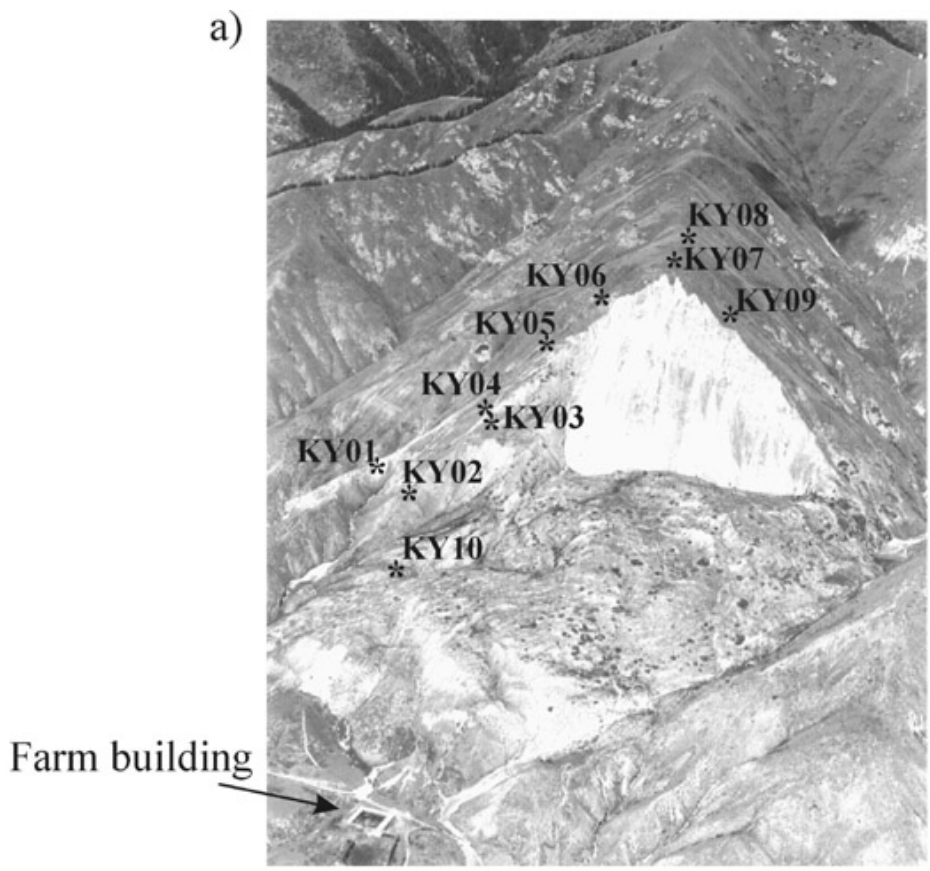

b)

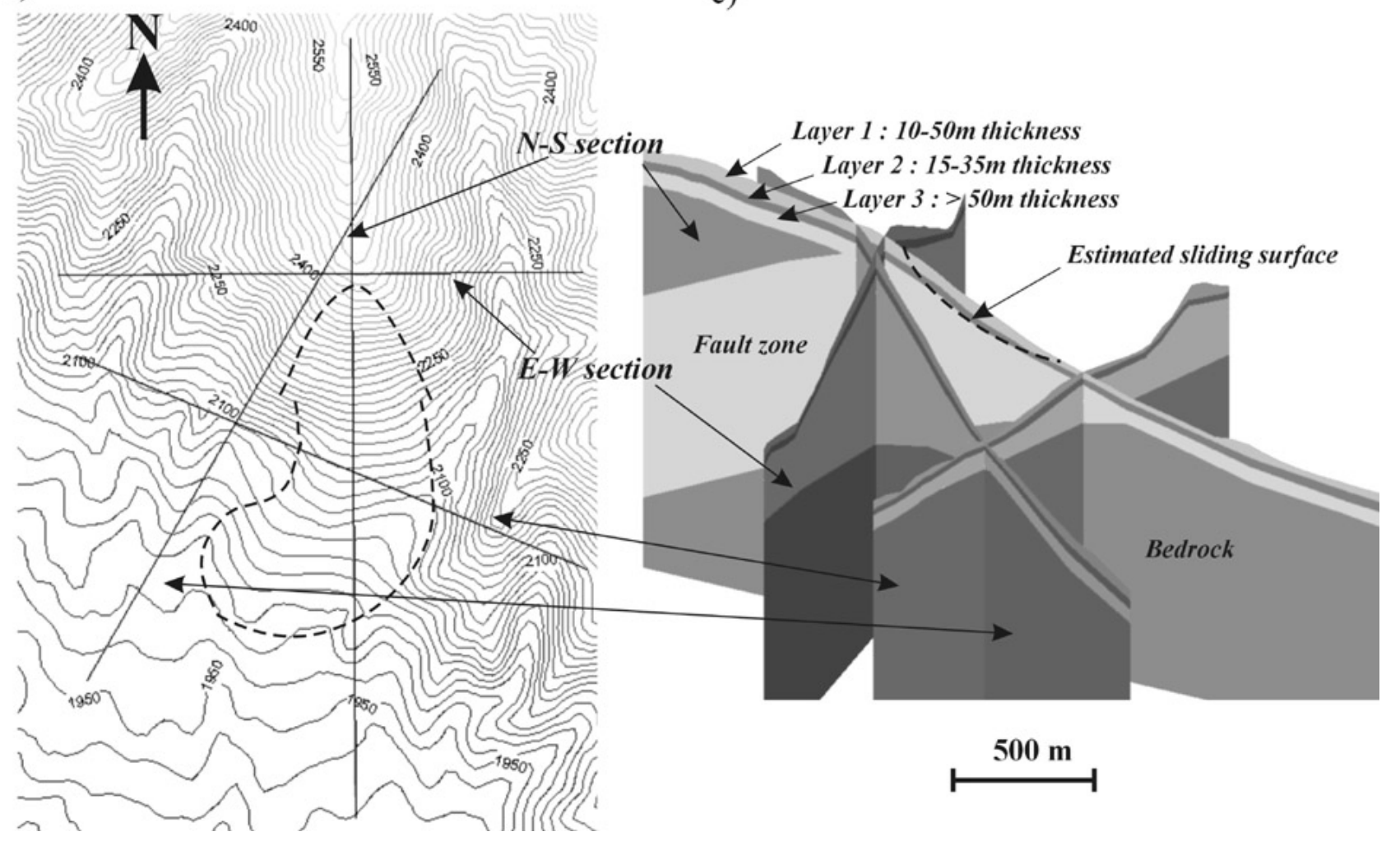

Fig. 2. (a) Helicopter Photograph of the Ananevo rockslide with location of seismic stations KY01 to KY10. For scale: the farm building has a rough side length of $50 \mathrm{~m}$. (b) Topographical map (prior to failure) showing the location of the cross-sections and the outline of the present-day rockslide scarp and tongue. (c) Cross-sections (including the modelled N-S and E-W sections) through the geophysical model previous to failure. Location of layers 1, 2 and 3, the fault and the bedrock as well as the estimated sliding surface along the N-S section are indicated. 


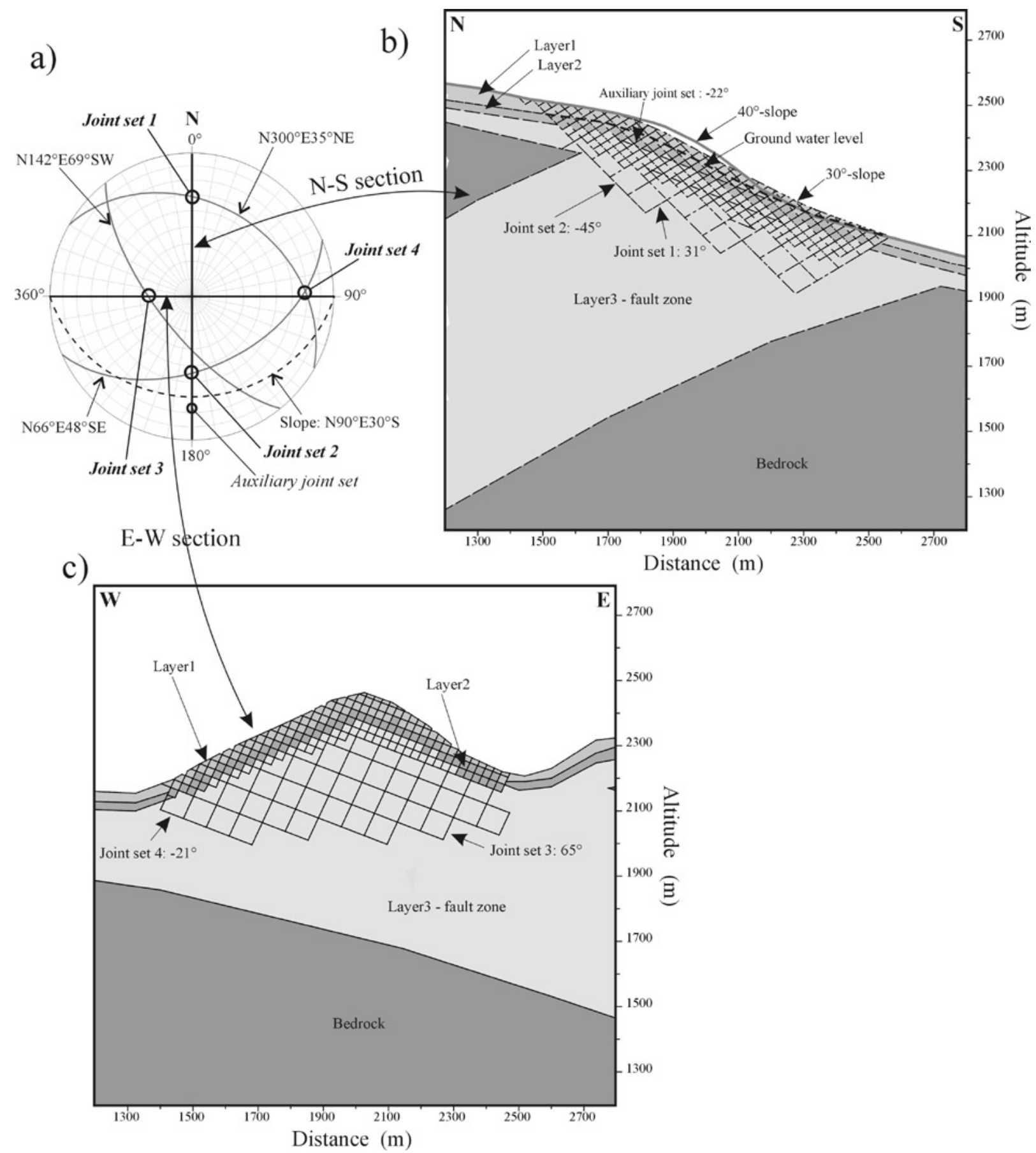

Fig. 3. (a) Lower-hemisphere stereoplot of mean slope angle and intersection of average measured fracture plains with the N-S and E$\mathrm{W}$ sections defining the orientation of joint sets 1 to 4 . The orientation of the auxiliary joint set is also plotted. Distinct element models of the Ananevo N-S section (b) and of the Ananevo E-W section (c) including 3 layers, fault zone, bedrock, joint structure, average groundwater level (in b) and two slope morphologies (in b).

for the applied UDEC software (Universal Distinct Element Code, Itasca). Although DEM codes are now almost ordinarily used for modelling geotechnical or rock-mechanics problems both in the static and dynamic regime, the employed code will be first briefly described.

\section{The distinct element modelling}

\subsection{The UDEC software}

The UDEC software has been designed for 2-D modelling and combines two different numerical techniques (Cundall, 


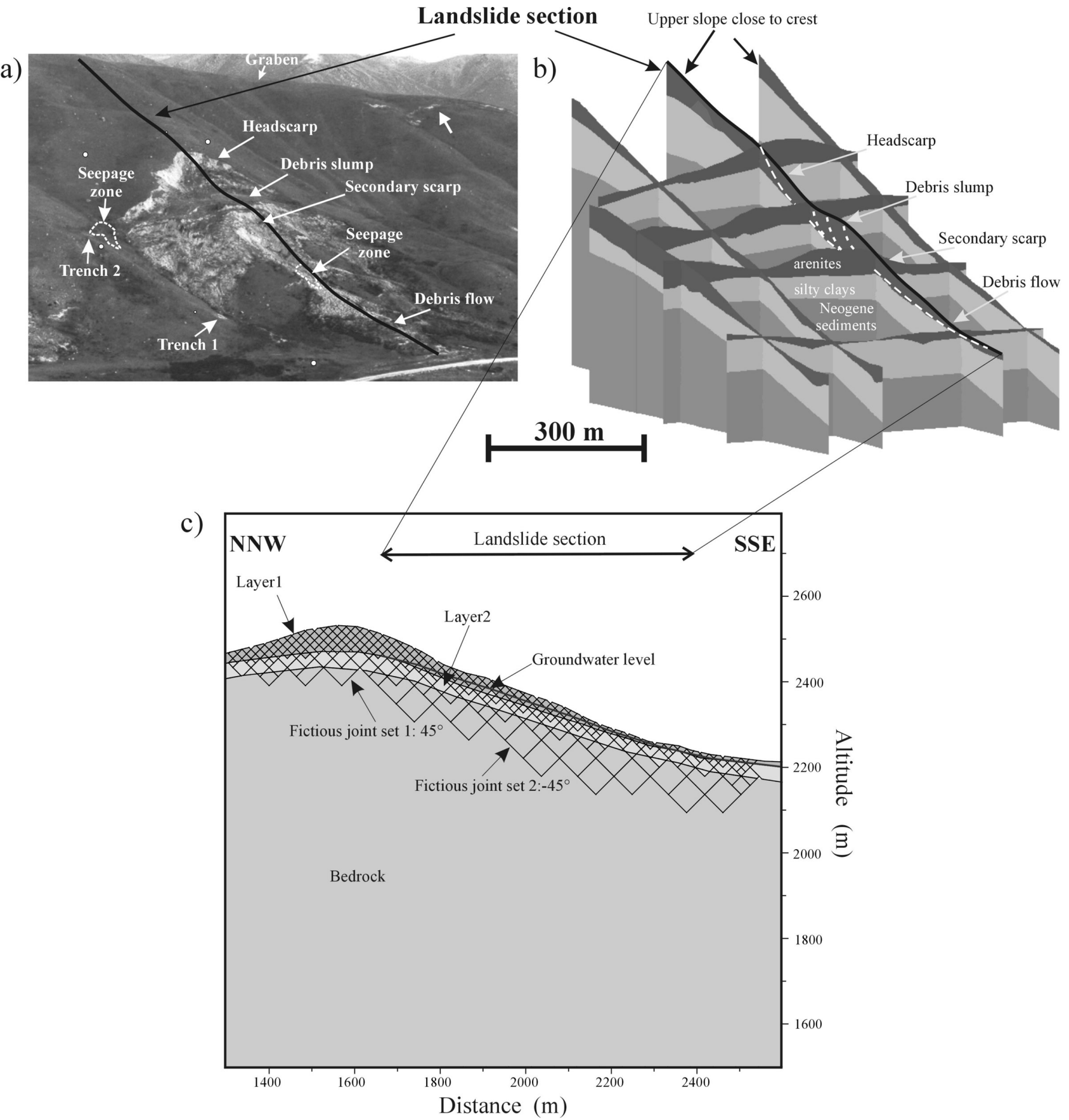

Fig. 4. (a) View on the Suusamyr landslide showing the landslide features (see also b), the main landslide section, the approximate location of the graben and of two trenches. (b) 3-D model showing the subsurface geology of the Suusamyr Landslide site, and the approximate location of sliding surfaces along the Landslide section. (c) Distinct element model of the Suusamyr NNW-SSE section including arenite (Layer 1) and silty clay layers (Layer 2) overlying the Neogene sediments (Bedrock), an auxiliary fracture system with two sets oriented + and $-45^{\circ}$ and the average groundwater level.

1980; Itasca, 1991): first, the distinct element method (DEM; Cundall, 1971) computing the behaviour of an assembly of distinct blocks (the elements) and the relative displacement between the elements (both slip and detachment); secondly, the finite difference method (FDM) determining the deformation of the material inside a block and the groundwater flow in the joints between blocks. In UDEC, a discontinuous material, such as a rock mass, is obtained from an initially intact block by defining one (or more) family of joints. By default, the obtained blocky system (the distinct element medium) is composed of rigid elements, which interact along the joints (contacts). Therefore, the deformation of the sys- 
Table 1. Distinct element parameters for Ananevo models

\begin{tabular}{|c|c|c|c|c|c|c|c|c|}
\hline \multirow[t]{2}{*}{ Layers } & \multicolumn{8}{|c|}{ Block material properties } \\
\hline & $\begin{array}{c}\mathrm{K} \\
(\mathrm{MPa})\end{array}$ & $\begin{array}{c}\mathrm{G} \\
(\mathrm{MPa})\end{array}$ & $\begin{array}{c}\text { coh1 } \\
(\mathrm{MPa})\end{array}$ & $\begin{array}{c}\operatorname{coh} 2 \\
(\mathrm{MPa})\end{array}$ & $\begin{array}{c}\text { fric1 } \\
\left({ }^{\circ}\right)\end{array}$ & $\begin{array}{l}\text { fric2 } \\
\left({ }^{\circ}\right)\end{array}$ & $\begin{array}{l}\text { dil } \\
\left({ }^{\circ}\right)\end{array}$ & dens \\
\hline Layer 1 & 778 & 293 & 0. & 4 & 40 & 45 & 10 & 1.8 \\
\hline Layer 2 & 3575 & 1650 & 1 & 5 & 40 & 45 & 10 & 2.0 \\
\hline Layer 3/fault & 21288 & 10977 & 2 & 10 & 45 & 50 & 10 & 2.3 \\
\hline Bedrock & 53000 & 31800 & 10000 & 10000 & 50 & 50 & 10 & 2.65 \\
\hline \multirow{2}{*}{\multicolumn{2}{|c|}{ Layers }} & \multicolumn{5}{|c|}{ Contact properties } & & \\
\hline & & $\begin{array}{c}\text { jkn } \\
(\mathrm{MPa})\end{array}$ & $\begin{array}{c}\mathrm{jks} \\
(\mathrm{MPa})\end{array}$ & $\begin{array}{c}\mathrm{jc} 1 \\
(\mathrm{MPa})\end{array}$ & $\begin{array}{c}\mathrm{jc} 2 \\
(\mathrm{MPa})\end{array}$ & $\begin{array}{l}\text { jfr1 } \\
\left({ }^{\circ}\right)\end{array}$ & $\begin{array}{l}\text { jfr2 } \\
\left({ }^{\circ}\right)\end{array}$ & \\
\hline \multicolumn{2}{|c|}{ Layer 1} & 1000 & 1000 & 0.1 & 0.4 & 30 & 40 & \\
\hline \multicolumn{2}{|c|}{ Layer 2} & 2000 & 2000 & 0.2 & 1 & 30 & 40 & \\
\hline \multicolumn{2}{|c|}{ Layer 3/fault } & 10000 & 10000 & 1 & 2 & 35 & 45 & \\
\hline \multicolumn{2}{|c|}{ Bedrock } & 10000 & 10000 & 10000 & 10000 & 45 & 50 & \\
\hline
\end{tabular}

block material properties: $\quad \mathrm{K}$ - bulk modulus, $\mathrm{G}$ - shear modulus, coh1 - lower cohesion (= tension), coh2 - higher cohesion (= tension), fric1 - lower friction angle, fric2 - higher friction angle, dil - dilation angle, dens - density

contact properties: $\mathrm{jkn}$ - normal contact rigidity, jks - tangential contact rigidity, jc1 - lower cohesion, jc2 - higher cohesion, jfr1 - lower friction angle, jfr2 - higher friction angle

tem is only due to the elastic compliance of joints, and to the relative (and significant) displacement at joints. If the compliance of the rock matrix is of relevance in the considered problem, each block can be subdivided into zones to enable internal deformation computed by FDM. The main advantage to subdivide the medium into distinct elements is to allow the system to evolve further than a continuous FD or FE continuum and to enable singular blocks to deform separately. In addition, since the complexity of the behaviour of a fractured system is mainly due to its discrete nature, relatively rough models can be used, in which simple constitutive relationships for the matrix (elastic or Mohr-Coulomb) and for the joints (elastic with Coulomb slip) can be successfully employed (in Table 1 the list of the used parameters is given).

If an elastic (or Mohr-Coulomb) behaviour is adopted for the matrix, the main source of energy dissipation is contact slip, which is in general insufficient to reproduce the real behaviour. For this reason, it is necessary to include a damping of the node velocities. Various types of damping can be used, but Rayleigh damping seems to be best adapted to dynamic problems (detailed explanation in Bathe and Wilson, 1976). Originally, it was created for the damping of the natural oscillation modes of elastic systems, similar to the viscous attenuation, but it can also be applied to a plastic medium. The Rayleigh damping is both proportional to the involved mass and the material stiffness and can be expressed by two factors, the critical damping ratio and the angular frequency. In the presented simulations, damping was not necessary in order to reproduce the initial (static) state because the force equilibrium was generally quickly reached, and it was intro- duced only for the following dynamic solicitation.

\subsection{The basic models}

The computations have been applied to the N-S and E-W sections across the 3-D Ananevo model prior to failure (Figs. 2c and 3). The model used for the Suusamyr site has been developed on the basis of the extrapolated Landslide (NNW-SSE) section across the 3-D Suusamyr model, but with a topography prior to the failure in 1992 (Fig. 4). The main elements in the numerical models are the surface layers and the underlying basement. Further blocks are defined by intersecting fracture or joint sets. In order to save computational time and to stabilize the computations, only the central part of the model (at about $2000 \mathrm{~m}$ along the horizontal axis, see Figs. 3b, c and 4c) in the vicinity of the surface has been subdivided by a close joint spacing into such blocks. Outside the region of interest (the slope surface), a wider spacing has been used and the contacts between the surface layers (present all over the surface) were glued: no slip or detachment is allowed along joints, which is obtained by setting a high value of cohesion and tensile strength. Other glued joints were introduced in order to enable a better zoning of the basement block.

By varying the geometry and the geotechnical parameters of the contacts and of the block materials, many different models were defined on the basis of the aforementioned cross-sections. Particular attention was paid to the influence of the elastic layering on the deformation mechanisms.

Before applying the dynamic conditions, the lithostatic and the steady-state seepage initial state were obtained by subjecting the blocky system to gravity force. Starting from 
this condition, simulations were run with various vertically propagating seismic loads applied to the models.

\subsubsection{Ananevo N-S section}

Considering that the topography of the Ananevo site before failure (in 1911) is not known, the initial slope morphology cannot be precisely determined. Therefore, two types of slope geometries were tested with the N-S section (Fig. 3b), one with a $30^{\circ}$-slope ( $30^{\circ}$ is the maximum slope angle) and one with a slightly steeper slope (maximum slope angle of $40^{\circ}$ ). The model is composed of 3 weathered rock layers, the bedrock and the fault zone. The contacts between layers are glued in order to avoid slip or detachment. Along the slope, the layer contacts are deformable but discontinuous due to the block structure described below. In some of the investigated models, the presence of the elastic layering was completely (or partially) "hidden", by keeping the elastic matrix parameters uniform all over the model. Thus, the slope behaviour could be checked for the same geometry without the interaction of superficial amplification effects.

In addition to the contacts between layers, two joint sets (Fig. 3a) have been introduced in most of the models according to the intersection of the profile with the average fracture planes: one set has a $45^{\circ}$ dip towards the south and the other dips $31^{\circ}$ towards the north (see Fig. 3b). The joint spacing is 15 or $25 \mathrm{~m}$ ( $25 \mathrm{~m}$ in Fig. $3 \mathrm{~b}$ ) between blocks close to the surface and $75 \mathrm{~m}$ at greater depth, where only small deformation occurs. For some simulations, an auxiliary fracture set with a $22^{\circ}$ off-slope dip and with higher shear resistance has been introduced (Fig. 3b).

The law defining the behaviour of the contacts is a Coulomb slip model applied to the entire joint area (in 2-D: a line). The behaviour of the block material is either elastic or elasto-plastic according to the Mohr-Coulomb model. Both contact and block material properties are shown in Table 1. The elastic properties were mostly derived from field data, whereas the plastic parameter values were defined within ranges given in literature (Hoek and Bray, 1981; Philipponnat, 1979). It can be inferred from this that the elastic properties are quite well constrained, while the values of the plastic parameters are affected by a high degree of uncertainty. Therefore, the modelling was performed with two types of shear strengths (Table 1), one defined by higher cohesion and friction angle values (coh2, fric2), the other by lower values (coh1, fric1).

Fractures are likely to present a weaker shear strength than the rock material itself, hence, lower shear strength parameter values were attributed to the joints. Since these properties are equally uncertain, two contact shear strengths were tested (Table 1), one with higher contact cohesion and friction angle values (jc2, jf2) and one with lower values (jc1, jf1). Most simulations were run with the lower contact and block material shear strength parameters; some did also take into account lubrication (very low cohesion and friction angle) along a possible sliding surface. For a few runs, groundwater has been introduced in the models and a steady-state flow algorithm was used to compute water pressures in the fracture system.

\subsubsection{Ananevo E-W section}

Additional distinct element models were constructed on the basis of the Ananevo E-W section across the mountain crest, even though it does not intersect the rockslide. The section was still used for many simulations since the prominent ridge-crest topography appears only along this profile and is thought to influence the seismic response of the site.

The models include the same components as the former ones except groundwater flow (Fig. 3c, Table 1). The joint orientation is adapted to the intersection of the E-W profile with the average measured fracture orientations (Fig. 3a): one set dips $65^{\circ}$ towards the west and one set dips $21^{\circ}$ towards the east (Fig. 3c). The latter orientation is approximately the dip of the intersection line between two joint families dipping to the NNE and to the SSE (Fig. 3a).

\subsubsection{Suusamyr landslide (NNW-SSE) section}

The Suusamyr models were designed in a similar way as the Ananevo models. They also present a topography before failure, surface layers and a bedrock (Fig. 4c). However, contrary to the Ananevo N-S section, the layer contacts are continuous all along the surface. They are glued (no slip and detachment) north and south of the Chet-Korumdy ridge, but the layers are allowed to slip below the ridge. Indeed, the layers correspond in this case to different geological units (Fig. 4): layer 1 is made of arenites, layer 2 is a silty clay layer and the bedrock is composed of compacted Neogene sediments. The elasto-plastic properties of the contacts and materials are shown in Table 2. Most of these properties could be directly inferred from field or laboratory measurements. Others, like the parameter values of the deeper-lying Neogene sediments, were determined on the basis of suggested value-ranges presented in literature (Hoek and Bray, 1981; Philipponnat, 1979).

Two fracture sets were added to the layer structure in order to allow the system to deform more intensively than a continuous medium. They further take into account ground ruptures along the slope existing before the earthquake (a more detailed description is given in Part A: Havenith et al., 2003). On the other hand, owing to the weak contrast between the block-material and the fracture shear strength (the latter is only $10 \%$ lower than the first, see Table 2 ), the medium corresponds to a quasi-continuum. In this regard, this soilsediment model differs significantly from the Ananevo rock models, where the shear strength of the block materials is several times larger than the shear strength along the contacts (compare sets coh1(2), fric1(2) with jc1(2), jf1(2) in the Tables 1 and 2).

\subsection{Static factor of safety}

For various models, a static factor of safety has been defined by means of the shear strength reduction technique 
Table 2. Distinct element parameters for the Suusamyr model

\begin{tabular}{|c|c|c|c|c|c|c|c|c|}
\hline \multirow[t]{2}{*}{ Layers } & \multicolumn{8}{|c|}{ Block material properties } \\
\hline & $\begin{array}{c}\mathrm{K} \\
(\mathrm{MPa})\end{array}$ & $\begin{array}{c}\mathrm{G} \\
(\mathrm{MPa})\end{array}$ & $\begin{array}{c}\text { coh1 } \\
(\mathrm{MPa})\end{array}$ & $\begin{array}{c}\text { coh2 } \\
(\mathrm{MPa})\end{array}$ & $\begin{array}{l}\text { fric1 } \\
\left({ }^{\circ}\right)\end{array}$ & $\begin{array}{c}\text { fric2 } \\
\left(^{\circ}\right)\end{array}$ & $\begin{array}{l}\text { dil } \\
\left({ }^{\circ}\right)\end{array}$ & dens \\
\hline Layer 1 & 565 & 115 & 0.018 & 0.025 & 30 & 37.5 & 5 & 1.7 \\
\hline Layer 2 & 6293 & 1280 & 0.06 & 0.088 & 24 & 30 & 5 & 2.0 \\
\hline Bedrock & 18692 & 6400 & 0.15 & 0.15 & 27 & 27 & 5 & 2.5 \\
\hline
\end{tabular}

\begin{tabular}{lcccccc}
\hline Layers & \multicolumn{5}{c}{ Contact properties } \\
& $\begin{array}{c}\mathrm{jkn} \\
(\mathrm{MPa})\end{array}$ & $\begin{array}{c}\mathrm{jks} \\
(\mathrm{MPa})\end{array}$ & $\begin{array}{c}\mathrm{jc} 1 \\
(\mathrm{MPa})\end{array}$ & $\begin{array}{c}\mathrm{jc} 2 \\
(\mathrm{MPa})\end{array}$ & $\begin{array}{c}\mathrm{jfr} 1 \\
\left({ }^{\circ}\right)\end{array}$ & $\begin{array}{c}\mathrm{jfr} 2 \\
\left(^{\circ}\right)\end{array}$ \\
\hline Layer 1 & 1000 & 1000 & 0.0162 & 0.0225 & 27 & 33.75 \\
Layer 2 & 2000 & 2000 & 0.054 & 0.079 & 21.6 & 27 \\
Bedrock & 5000 & 5000 & 0.135 & 0.135 & 24.3 & 24.3 \\
\hline
\end{tabular}

see annotation explanation below Table 1 .

(Zienkiewicz et al., 1975). This technique still commonly used in numerical modelling (Dawson and Roth, 1999) is based on the definition of the factor of safety as ratio of the actual shear strength to the minimum shear strength required to prevent failure. A series of simulations are run, each with a new set of reduced cohesion $(C)$ and friction angle $(\phi)$ values determined from the following equations.

$C^{\text {trial }}=\frac{1}{F^{\text {trial }}} C$

$\phi^{\text {trial }}=\arctan \left(\frac{1}{F^{\text {trial }}} \tan \phi\right)$

The reduction factor $F$ is increased at each new simulation and corresponds to the trial factor of safety. At failure, the trial factor of safety equals the factor of safety of the initial slope stability problem. Numerically, failure is detected when static modelling does not reach equilibrium, i.e. inertia forces (the so-called "unbalanced forces") are larger than a pre-defined threshold value (Dawson and Roth, 1999). In the case of the present static slope stability analyses, no unique threshold value of unbalanced forces was pre-defined due to the varying complexity of the stability problems. Rather, the global behaviour of the slope model was observed and simulations were considered as converging when initial nodal velocities due to the unbalanced forces decreased with time down to very small values $(<\sim 1 \mathrm{~mm} / \mathrm{s})$.

\subsubsection{Ananevo N-S section}

The two main types of Ananevo N-S models analysed with regard to static stability differ in the slope geometry: the one has a $30^{\circ}$-slope and the other a $40^{\circ}$-slope (see also above and Fig. 3b). These two models were examined under dry and groundwater flow conditions including all other geometrical features (layers, joints, etc.) and lower block and contact shear strengths (coh1, fric1 and jc1, jf1 in Table 1). By gradually reducing the shear strength of all materials and contacts, the simulations revealed the following factors of safety $(F s)$ :

- 30॰-slope, dry conditions: $F s>10$

- 30-slope, with water-flow conditions : Fs $>10$

- 40-slope, dry conditions : Fs $>6$

- $40^{\circ}$-slope, with water-flow conditions : Fs $\sim 4$

These values are only rough estimates of the factor of safety, but all indicate a very high stability of the slope, even under water-flow conditions. This is principally due to the stable orientation of the joints that does not enable off-slope slip.

\subsubsection{Ananevo E-W section}

The factor of safety of the E-W section was calculated under dry conditions using the model shown in Fig. 3c. The simulations with lowered shear strength showed that first instability occurs along the contacts below the mountain crest dipping $21^{\circ}$ towards the East (Fig. 3c). The related factor of safety is about $2.7-3$, i.e. much lower than for the N-S section, but still sufficiently high to be able to exclude any static trigger mechanisms under dry conditions.

\subsubsection{Suusamyr Landslide (NNW-SSE) section}

The present section allowed us to validate the shear strength technique through comparison with a limit analysis (Janbu, 1973) applied to the central part of the model shown in Fig. 4c, corresponding to the Landslide section. The analysis yielded a factor of safety of 1.14 for an almost identical geometry including the presence of groundwater (Havenith et al., 2000). The factor of safety defined with UDEC amounts to $1.43-1.56$ without the interaction of groundwater. However, under flow conditions the $F s$ could be constrained to an interval between 1.09 and 1.18, i.e. a range of values including the factor of safety defined by limit analysis. These 
low $F s$ values indicate that the slope is marginally stable under static conditions, which may also explain the presence of instability features along the slope before the earthquake (Part A: Havenith et al., 2003).

\section{Dynamic distinct element modelling}

The static numerical analyses showed that the Ananevo N$\mathrm{S}$ and $\mathrm{E}-\mathrm{W}$ models are stable under static conditions, while the Suusamyr slope is close to static instability and likely to fail for weak seismic loads. Indeed, according to former limit analyses sliding along this slope is supposed to be triggered for an acceleration value of only $0.05 \mathrm{~g}$ (Havenith et al., 2000).

Using the UDEC code, dynamic stability was examined with regard to various seismic inputs propagating vertically through the model as plane waves. In most cases, the load was composed of 1 to 12 cycles of a $2 \mathrm{~Hz}$ (also 1 and $4 \mathrm{~Hz}$ ) Ricker wavelet (duration of $1 \mathrm{~s}$ to $12 \mathrm{~s}$ ) generally applied as horizontal vibration ( $\mathrm{S}$-wave). The amplitudes were varied in the range between $0.005 \mathrm{~m} / \mathrm{s}$ and $0.625 \mathrm{~m} / \mathrm{s}$. The Ricker wavelet is commonly used as input load for modelling earthquake ground motions since it has a broad energy content and a wave period $T_{D}$ that can be directly inferred from the central frequency $v_{M}$ by the formula:

$T_{D}=(\sqrt{6} / \pi) v_{M}$

Another type of seismic load occasionally used is a seismogram simulated with the stochastic method of Boore (1996) for several magnitudes and epicentral distances. Even if they are simulated, the seismograms will much better reproduce the input shaking of an earthquake than the simple Ricker wavelets. On the other hand, the latter are much better adapted to control the response of the model to varying source amplitude, frequency and duration. This is the reason why only simulations with Ricker sources are included in the following parametric analysis; modelling with simulated seismograms did, in fact, not significantly add to the goal of the study. Further, principally wavelets with a central frequency of $2 \mathrm{~Hz}$ were introduced since the energy content covers a frequency range between at least 0.5 and $5 \mathrm{~Hz}$ that is common for earthquake sources.

\subsection{Dynamic modelling of elastic strains}

Before large deformations were simulated with UDEC, elastic ground motion dynamics had been computed for homogeneous and layered models including a fault zone. Therefore, an elastic relationship was used in these simulations for the matrix material and all the joints were glued. In order to check the reliability of the simulations, particularly with regard to the applied Rayleigh damping parameter values, some of them were compared with other modelling results. These were obtained with a finite and spectral element code (AHNSE) developed by Faccioli et al. (1997) for accurate dynamic visco-elastic modelling. Wave propagation was simulated with the same plane wave source, a $2 \mathrm{~Hz}$ Ricker wavelet, and almost identical model geometries, differing only in some features that are related to meshing constraints (e.g. blocks inside UDEC models). In Fig. 5, results produced for the Ananevo E-W section model, composed of homogeneous bedrock or layered with fault (runs a_ew1 and a_ew2 in Table 3), are shown in terms of standard spectral ratios (SSR) between 0.5 and $5 \mathrm{~Hz}$. The latter are here defined in the same way as experimental SSR, i.e. as ratios between the spectra computed over the mountain ridge and a spectrum computed at the surface of a flat homogenous bedrock model. By comparing the various SSR distributions along the profile (Fig. 5), it can first be observed that both simulations with AHNSE and with UDEC predict a similar low average amplification level for the simple bedrock model (Fig. 5a). A comparable high level is produced for the model with surface layers and fault (Fig. 5b). With the latter model, the two types of modelling produce highest amplification (larger than 10) at low frequency in the proximity of the mountain crest, which compares also with experimental SSR (Havenith et al., 2003). On the other hand, the simulation results differentiate for the higher frequency response and for the site effects along the slopes. The latter difference can be explained by a slightly smoother surface layer geometry used for the UDEC models inducing minor deamplification. The increasing misfit at higher frequencies probably results from the specific attenuation behaviour computed by the two types of modelling: viscous attenuation in the AHNSE models and Rayleigh damping in the UDEC models (using 0.01 for the critical damping ratio and $2 \mathrm{~Hz}$ for the angular frequency, which is identical to the source frequency).

From a general point of view, it can, however, be noticed that the results obtained with the two codes are relatively similar. Since the AHNSE code has proved to be a reliable tool in visco-elastic modelling ground motions (Paolucci et al., 1999), these comparisons validate the use of UDEC for seismic ground motion simulations. Comparisons between the response of a homogeneous model and a layered one were also performed for the other two sections, the Ananevo NS section (Fig. 6) and the Suusamyr Landslide section (Fig. 7, see Tables 2 and 3 for characteristics). These spectral ratios or transfer functions ( $T F$ ) were not, however, calculated with respect to a spectrum of a surface receiver on a flat bedrock model but with regard to the spectrum of the Ricker source. Since the surface receiver - source spectrum ratios are two times larger than respective SSR ( $2=$ the factor of a flat surface reflection), an amplification scale ranging from 1 to 40 has been defined (see next figures). In order to compare the following $T F$ distributions with the previous ones, they need to be divided by 2 (compare Fig. 8a with Fig. 5b).

From Figs. 6 and 7, it can be seen that maximum factors of 40 (SSR of 20) are even exceeded in some locations of the Ananevo N-S and Suusamyr sections. Highest amplification along the Ananevo mountain (Fig. 6) appears at lower frequencies in the upper parts of the slopes, just as shown by simulations with the Ananevo E-W section (Fig. 5b) and by 
a)

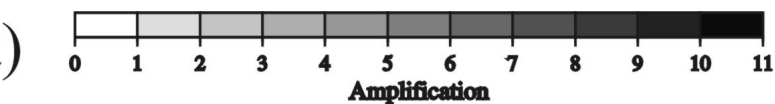

b)
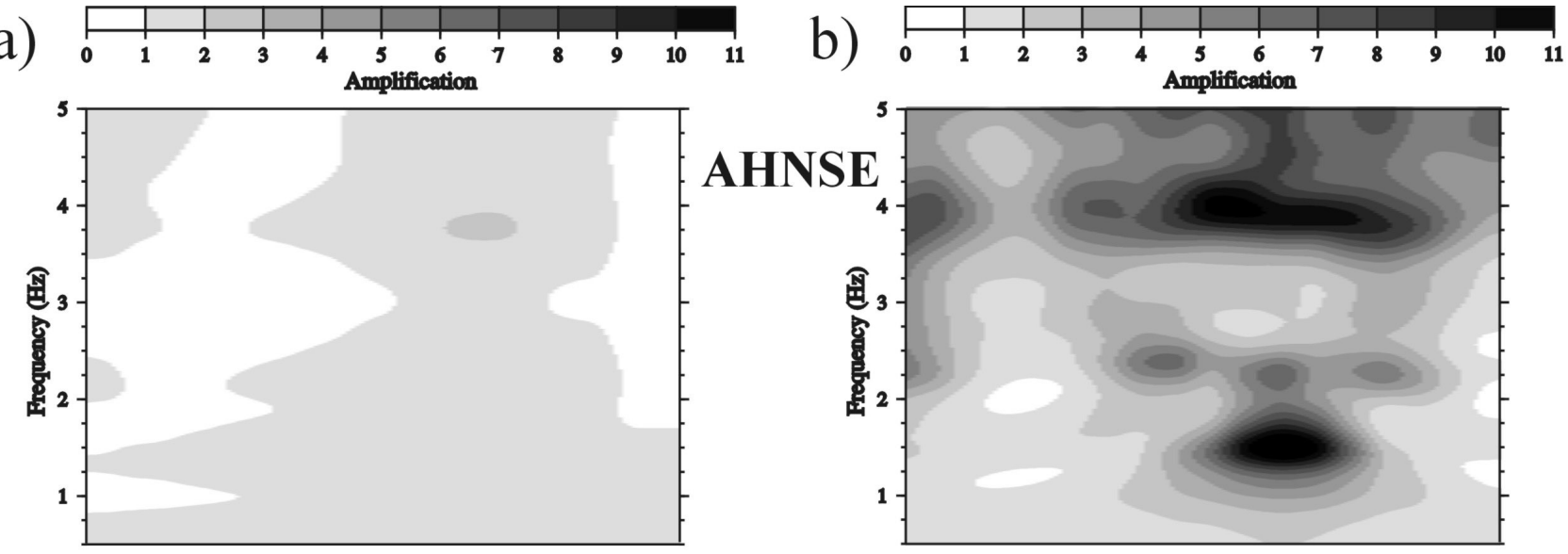

AHNSE
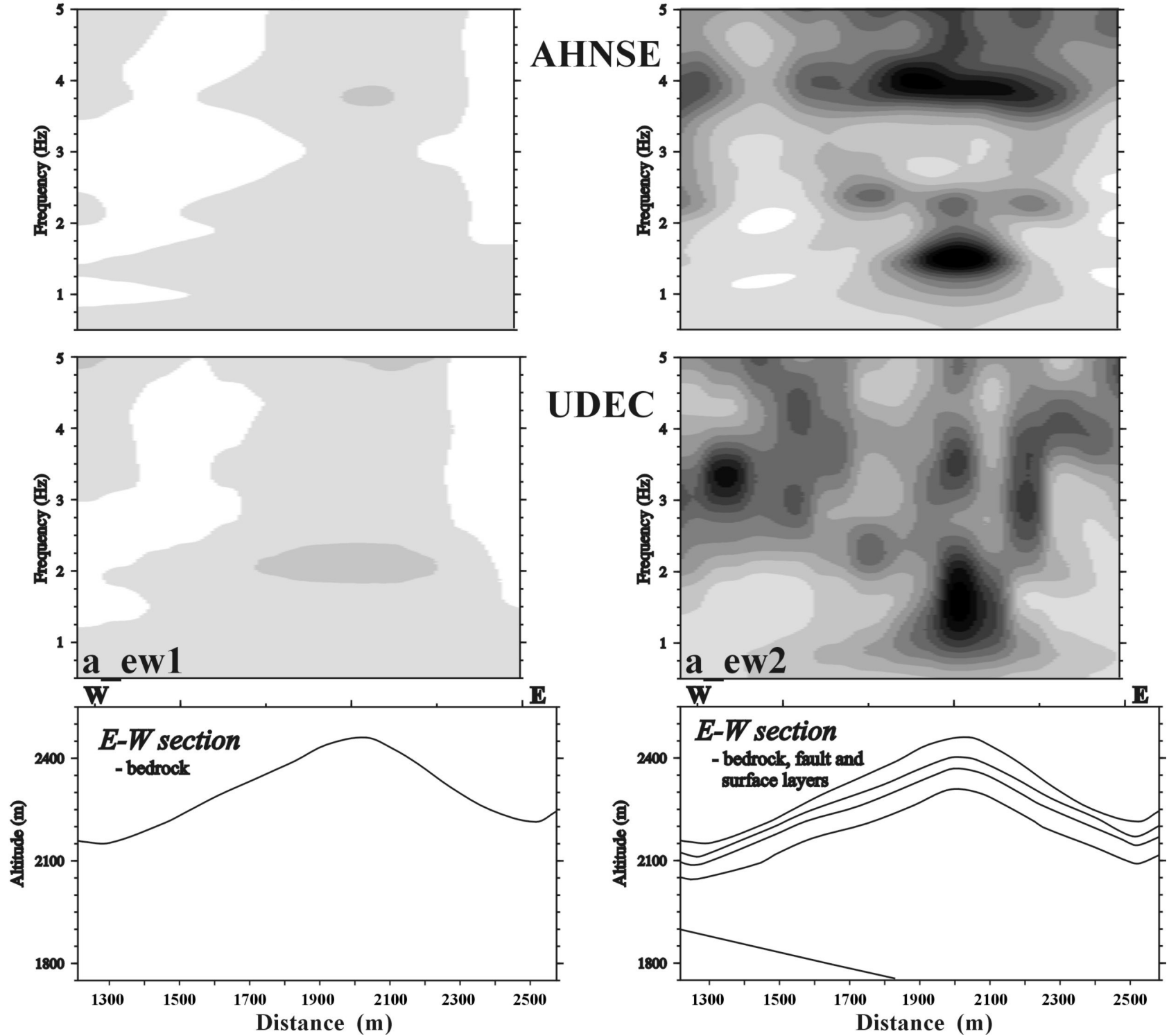

Fig. 5. Comparison between SSR distributions (surface receiver as reference) over the Ananevo E-W section simulated with AHNSE (above) and UDEC (below) for homogeneous (a) and heterogeneous (b) visco-elastic models.

the experimental SSR mentioned above. The response simulated for the Suusamyr site reveals similar characteristics as the one modelled with the Ananevo N-S and E-W sections: lower amplification values produced for the homogeneous model, highest amplification at low frequencies close to the ridge-crest within the heterogeneous model. The enhanced shaking in the crest region within the surficial layers is connected with effects of elastic strain-focusing and indicates a susceptibility to incipient failure. Its influence on large slope movements in connection with other geologic factors will be examined in the following.

\subsection{Dynamic modelling of plastic deformation}

A major problem involved in the transition from elastic to plastic deformation is the non-linear behaviour of the material. In the lack of comprehensive geotechnical information, we decided to disregard some specific features of the behaviour of the involved materials, such as the decrease of the shear modulus with increasing strain. Anyway, it is worth noting that the main source of non-linearity (the irreversible behaviour of joints) is automatically implemented in DEM models. Shear strength reduction along the joints has neither been taken into consideration in the following simula- 
Table 3. Changing characteristics between presented model types

\begin{tabular}{|c|c|c|c|c|c|c|c|c|}
\hline \multirow{2}{*}{$\begin{array}{l}\text { Run } \\
\text { Ananevo } \\
\text { E-W section }\end{array}$} & \multicolumn{8}{|c|}{ Modelling characteristics } \\
\hline & Slope & $\begin{array}{c}\text { Joint } \\
\text { structure }\end{array}$ & $\begin{array}{c}\text { Elastic } \\
\text { materials }\end{array}$ & $\begin{array}{l}\text { Shear } \\
\text { strength }\end{array}$ & $\begin{array}{l}\text { Groundw. } \\
\text { level }\end{array}$ & Cycles & $\begin{array}{l}\text { Ampl. } \\
(\mathrm{m} / \mathrm{s})\end{array}$ & $\begin{array}{l}\text { Freq. } \\
(\mathrm{Hz})\end{array}$ \\
\hline a_ew1 & / & / & uniform & / & l & 1 & 0.005 & 2 \\
\hline a_ew2 & / & I & layer-fault & l & I & 1 & 0.005 & 2 \\
\hline a_ew3 & / & 2 sets- 25 & layer-fault & jc1,jfr1 & I & 1 & 0.005 & 2 \\
\hline a_ew4 & / & 2 sets- 25 & layer-fault & jc1,jfr1 & I & 1 & 0.025 & 2 \\
\hline a_ew5 & / & 2 sets- 25 & layer-fault & jc1,jfr1 & / & 1 & 0.125 & 2 \\
\hline a_ew6 & / & 2 sets -25 & layer-fault & jc1,jfr1 & / & 1 & 0.625 & 2 \\
\hline a_ew7 & / & 2 sets- 25 & layer-fault & jc1,jfr1 & / & 12 & 0.625 & 2 \\
\hline a_ew8 & / & 2 sets -25 & layer-fault & $\begin{array}{l}\text { jc1,jfr1 } \\
\text { coh1,fric1 }\end{array}$ & I & 12 & 0.625 & 2 \\
\hline \multicolumn{9}{|l|}{$\begin{array}{l}\text { Ananevo } \\
\mathrm{N}-\mathrm{S} \text { section }\end{array}$} \\
\hline a_ns1 & $30^{\circ}$ & I & uniform & I & I & 1 & 0.005 & 2 \\
\hline a_ns2 & $30^{\circ}$ & I & layer-fault & I & I & 1 & 0.005 & 2 \\
\hline a_ns3 & $40^{\circ}$ & 3 sets -15 & layer-fault & $\begin{array}{c}\text { jc1,jfr1 } \\
\text { coh1,fric1 }\end{array}$ & I & 4 & 0.625 & 2 \\
\hline a_ns4 & $40^{\circ}$ & 3 sets- 15 & uniform & $\begin{array}{c}\text { jc1,jfr1 } \\
\text { coh1,fric1 }\end{array}$ & I & 4 & 0.625 & 2 \\
\hline a_ns5 & $40^{\circ}$ & 3 sets- 15 & inv.lay-fault & $\begin{array}{c}\text { jc1,jfr1 } \\
\text { coh1,fric1 }\end{array}$ & I & 4 & 0.625 & 2 \\
\hline a_ns6 & $30^{\circ}$ & 3 sets- 25 & layer-fault & jc1,jfr1 & I & 1 & 0.625 & 2 \\
\hline a_ns7 & $30^{\circ}$ & 3 sets- 25 & layer-fault & jc1,jfr1 & I & 1 & 0.625 & 1 \\
\hline a_ns8 & $30^{\circ}$ & 3 sets- 25 & layer-fault & $\mathrm{jc} 1, \mathrm{jfr} 1$ & I & 1 & 0.625 & 4 \\
\hline \multicolumn{9}{|c|}{$\begin{array}{l}\text { Suusamyr } \\
\text { Landslide section }\end{array}$} \\
\hline suus1 & I & / & uniform & I & I & 1 & 0.005 & 2 \\
\hline suus2 & I & I & layer & I & I & 1 & 0.005 & 2 \\
\hline suus3 & I & 2 sets- 15 & layer & $\begin{array}{c}\text { jc1,jfr1 } \\
\text { coh1,fric1 }\end{array}$ & I & 12 & 0.625 & 2 \\
\hline suus4 & I & 2 sets- 15 & layer & $\begin{array}{c}\text { jc1,jfr1 } \\
\text { coh1,fric1 }\end{array}$ & high & 4 & 0.625 & 2 \\
\hline suus5 & I & 2 sets -15 & layer & $\begin{array}{c}\text { jc1,jfr1 } \\
\text { coh1,fric1 }\end{array}$ & medium & 4 & 0.625 & 2 \\
\hline
\end{tabular}

slope: maximum slope angle; joint structure: number of joint sets ( 2 or 3 or none) with a 15 or $25 \mathrm{~m}$ joint spacing; elastic materials: type of geometry characterized by changing elasticity parameters (uniform, layers or layers and fault), inv.lay marks a layer geometry with increasing thickness down the slope; shear strength: contact shear strength (jc,jfr) and block material shear strength parameters (coh,fric); groundw. flow: groundwater flow computed or not (/); cycles: number of propagated Ricker wavelets (1-12); ampl.: peak-amplitude of one cycle $(0.005-0.625 \mathrm{~m} / \mathrm{s})$; freq.: central frequency $(1-4 \mathrm{~Hz})$.

tions, which may, therefore, be considered as relatively simple from a geomechanical point of view. On the other hand, the modelling was preformed at a higher degree of structural and lithological complexity since these were the principal factors analysed here. This does not, however, mean that shear strength reduction is thought to be insignificant. It was, actually, introduced in another type of modelling applied to the development of landslide processes. Respective results will be roughly outlined at the end but will not be detailed since they do not contribute to the goal of the paper.

\subsubsection{The Ananevo E-W section}

Plastic deformation can be initiated in different ways, but in the domain of seismic slope stability the amplitude of the shaking is without doubt a dominant factor. Therefore, the effect of the amplitude was the subject of most simulations. In order to make a connection with the previous results, outputs are first analysed in terms of transfer function $(T F)$ distributions beginning with the one computed for the purely elastic model (a_ew2 in Fig. 8a). These simulation results are the same as in Fig. 5b, but with the source spectrum 

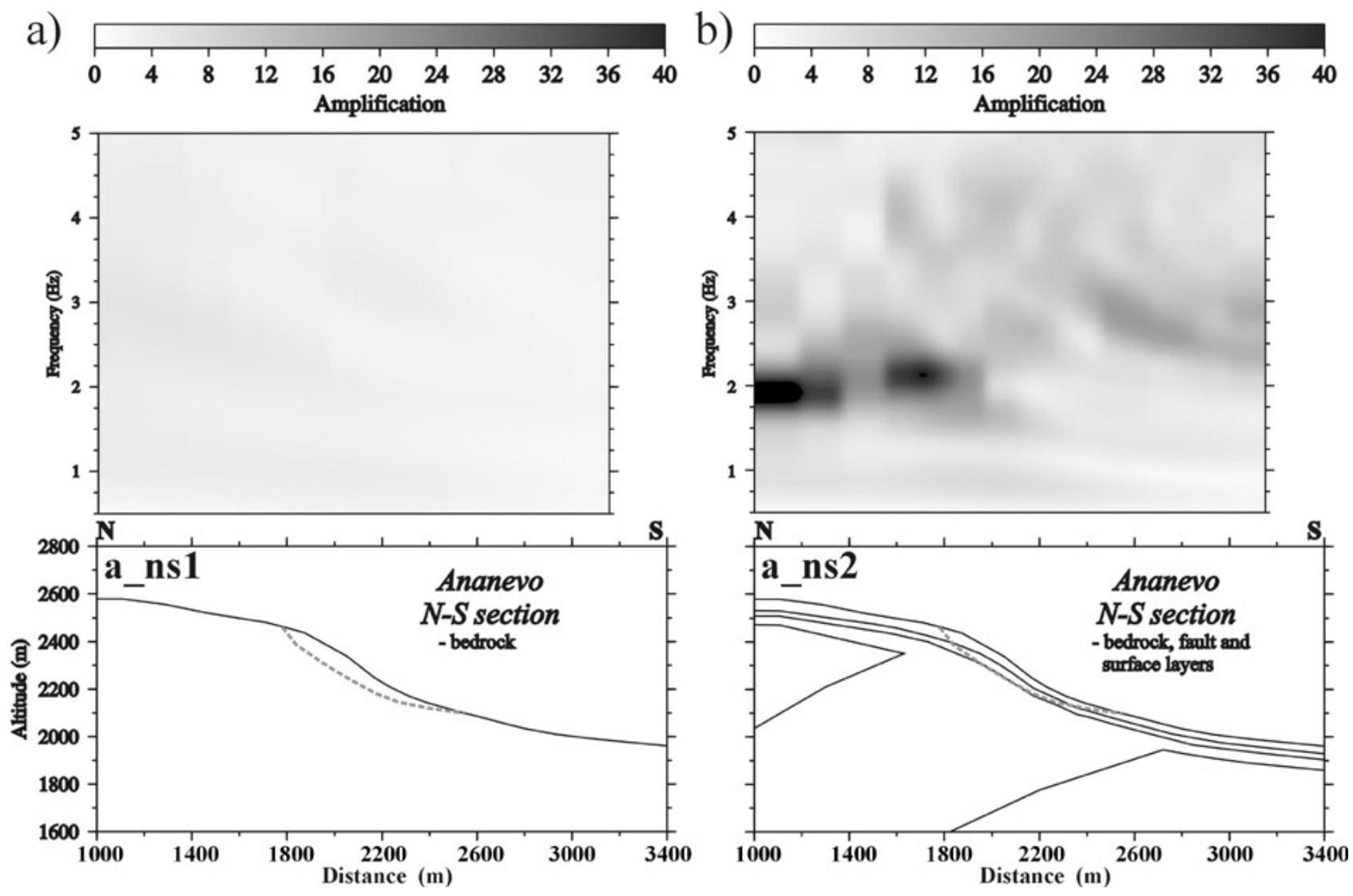

Fig. 6. Comparison between transfer function (source as reference) distributions over the Ananevo N-S section simulated with UDEC for homogeneous (a) and heterogeneous (b) elastic models.

as denominator in the spectral ratio. Hence, the amplification factors are much higher than in Fig. 5b. The same source, i.e. a $2 \mathrm{~Hz}$ Ricker wavelet with a $0.005 \mathrm{~m} / \mathrm{s}$ amplitude (the corresponding accelerogram has a peak amplitude of about $0.006 \mathrm{~g}$ at $2 \mathrm{~Hz}$ ), was also introduced into an equivalent model cut into elastic blocks with plastic block contacts (a_ew3 using jc1 and jf1 along the contacts, see also Table 3).

Related $T F$ distributions (Fig. 8b) are basically similar to the former results. The elastic block model with plastic contacts produces, however, some effects at higher frequencies close to the crest that are enhanced for a larger source amplitude $(0.025 \mathrm{~m} / \mathrm{s}$, see a_ew4 in Fig. 8c). Further accentuation of the seismic input induces larger $T F$ values at very low frequency around the crest (Fig. 8d and 8e) where previously high frequencies had been amplified.

From the comparison between the four latter distributions, it can be inferred that the initial activation of the contacts close to the crest is marked by high-frequency vibration. With increasing shaking amplitude, this response turns into long period-movements and finally into plastic deformation along the contacts (at infinitely long period $=0 \mathrm{~Hz}$ ), mainly along the crest where the elastic amplification is the highest. The type of deformation can be inferred from the block plots in Fig. 9 presenting the response of models to $12 \mathrm{~S}$ wave cycles with a peak amplitude of $0.625 \mathrm{~m} / \mathrm{s}$ (accelera- tion of $\sim 0.75 \mathrm{~g}$ at $2 \mathrm{~Hz}$ ). The plots show the initial block structure overlaid by the shear displacements along the contacts and the final geometry with 5-times amplified nodal displacements induced on the Ananevo mountain ridge by 12 cycles with a peak amplitude of $0.625 \mathrm{~m} / \mathrm{s}$ (acceleration of $\sim 0.75 \mathrm{~g}$ at $2 \mathrm{~Hz}$ ). The model with elastic blocks and plastic contacts (Fig. 9a) indicates that sliding preferentially occurs along joints below the crest dipping eastward. Slip occurs also inside the ridge composed of plastic blocks (Fig. 9b: model a_ew8 using coh1, fric1 for the block materials). For the same shaking intensity, final shear displacements are, however, less pronounced. On the other hand, additional deformation mechanisms that can be described as tilting and bending become active in the plastic block model. The latter corresponds to an off-slope rotation of the rock columns resulting in west- and upward displacements of the nodes (see arrows in Fig. 9b). This process seems to be specific for a plastic block material behaviour since it is produced along the western slope where the elastic block model does not show any deformation.

\subsubsection{The Ananevo N-S section}

Similar results were obtained with the Ananevo N-S section: bending occurs only along the southern slope composed of 
a)
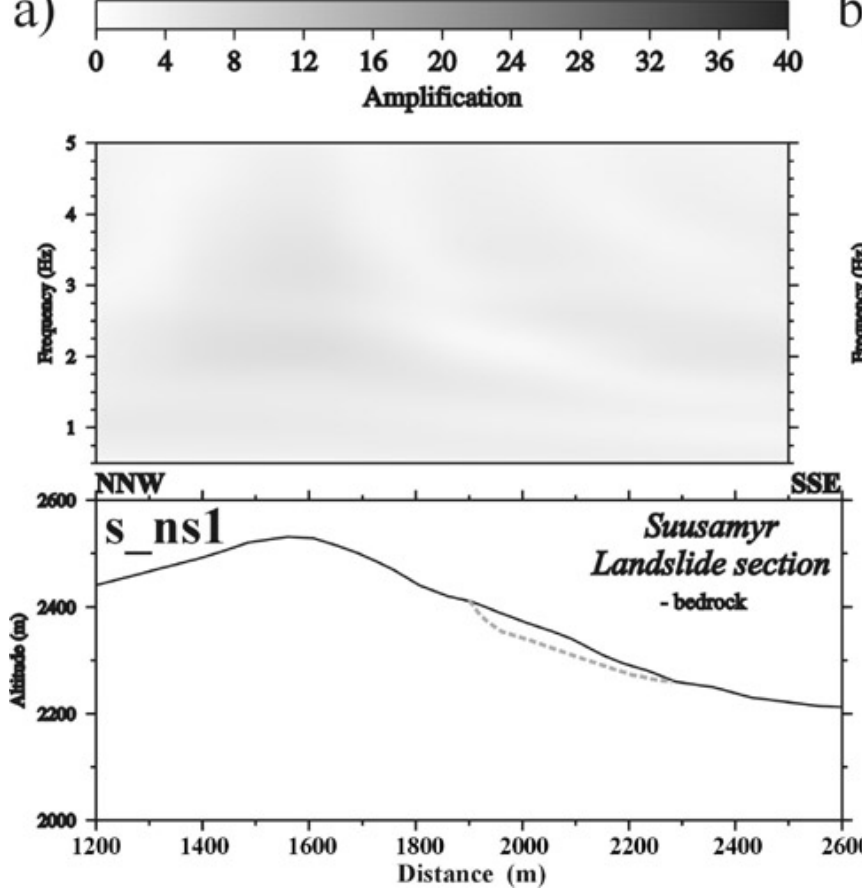

b)
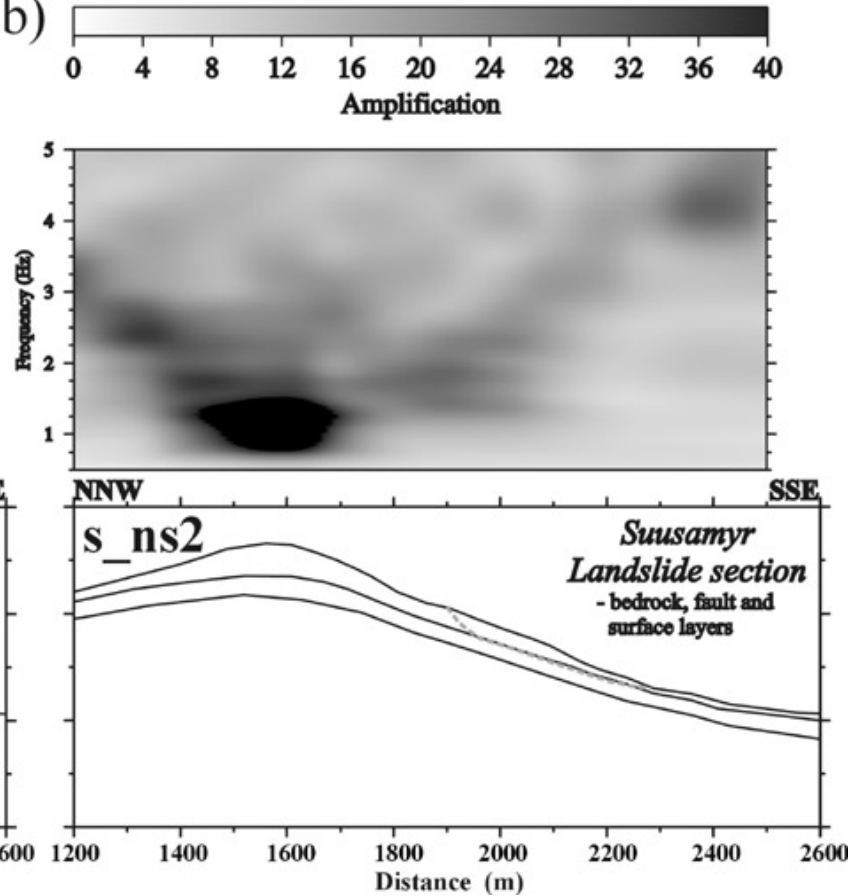

Fig. 7. Comparison between transfer function (source as reference) distributions over the Suusamyr N-S section simulated with UDEC for homogeneous (a) and heterogeneous (b) elastic models.

plastic blocks separated by plastic contacts. From a series of simulations it could be inferred that the amount of nodal displacements directly depends on the amplitude and the duration of the input signal. Largest displacements of several meters were produced by bending of plastic block colons, while sliding movements were much less pronounced than in the E-W section. Indeed, at the Ananevo site, the joint orientation does apparently only enable clear slip towards the east (Fig. 9). Along the N-S section, the fracture system is not favourable for sliding since the southward dipping joints are steeper than the slope topography; one may even wonder how the rockslide could develop in this direction. Henceforth, the origin of the instability cannot be inferred from the pre-existing joint structure alone and the activation of a sliding surface needs to be involved. In order to allow the slope to slide down, this surface must have a lower dip than the slope $\left(<30^{\circ}\right)$ intersecting the initial block system. The creation of such a structure cannot be modelled because rupture across the blocks (even if they are plastic) is prohibited by the code. For modelling purposes, the existence of the surface is, therefore, presupposed, but its initiation will be discussed later on. Possible sliding surfaces were introduced as auxiliary joint set dipping either $22^{\circ}$ (see Fig. 3 b) or $25^{\circ}$ southward. Simple sliding mechanisms are, however, inhibited by the fact that the fractures do not intersect the surface topography and by a high contact shear strength (a cohesion of $0.5 \mathrm{MPa}$ and a friction angle of $35^{\circ}$ ) similar to the block material shear strength of the two upper layers. As a result, the static factor of stability was almost not affected by the addition of the fractures (the $F s$ is still larger than 4 in the case of a steep slope). Four $0.625 \mathrm{~m} / \mathrm{s} \mathrm{S}$-wave cycles were applied to the three following models with pre-existing and additional joint sets dipping $25^{\circ}$ southward (Fig. 10) and presenting a steep slope morphology, identical block and contact shear strengths (plastic blocks and contacts), but a different elastic layering. Figure 10a presents outputs of the simulations with the model including the observed elastic layer structure: three weathered rock layers overlying the bedrock with an increasing thickness of the weathered part towards the hilltop. This situation is reversed in the model in Fig. 10c with thicker low-velocity layers at the foot of the slope corresponding, for example, to large colluvium masses. The model in Fig. 10b is only composed of elastic bedrock (but still with plastic block and contact material layering). Respective results are shown in terms of time-distance distributions of $x$-velocities (above) and $x$-displacements (below). It can be observed from the various plots that the models with elastic layering (Figs. 10a and c) produce much larger final displacements than the model composed of elastic bedrock only (Fig. 10b). Since the displacements are the result of integration of the corresponding velocity time-histories, the larger horizontal displacements can be directly linked to the larger $x$-velocity amplitudes and widened $x$-velocity cycles. The two latter features result from amplification effects due to the presence of surface layers as shown in Fig. 6b. On the other hand, the type of layer geometry seems to be less important. Indeed, stronger ground motions are produced by both the model with a thick hilltop layer and the one with a thicker layer at the foot of the slope.

The shaking intensity is obviously a major factor control- 


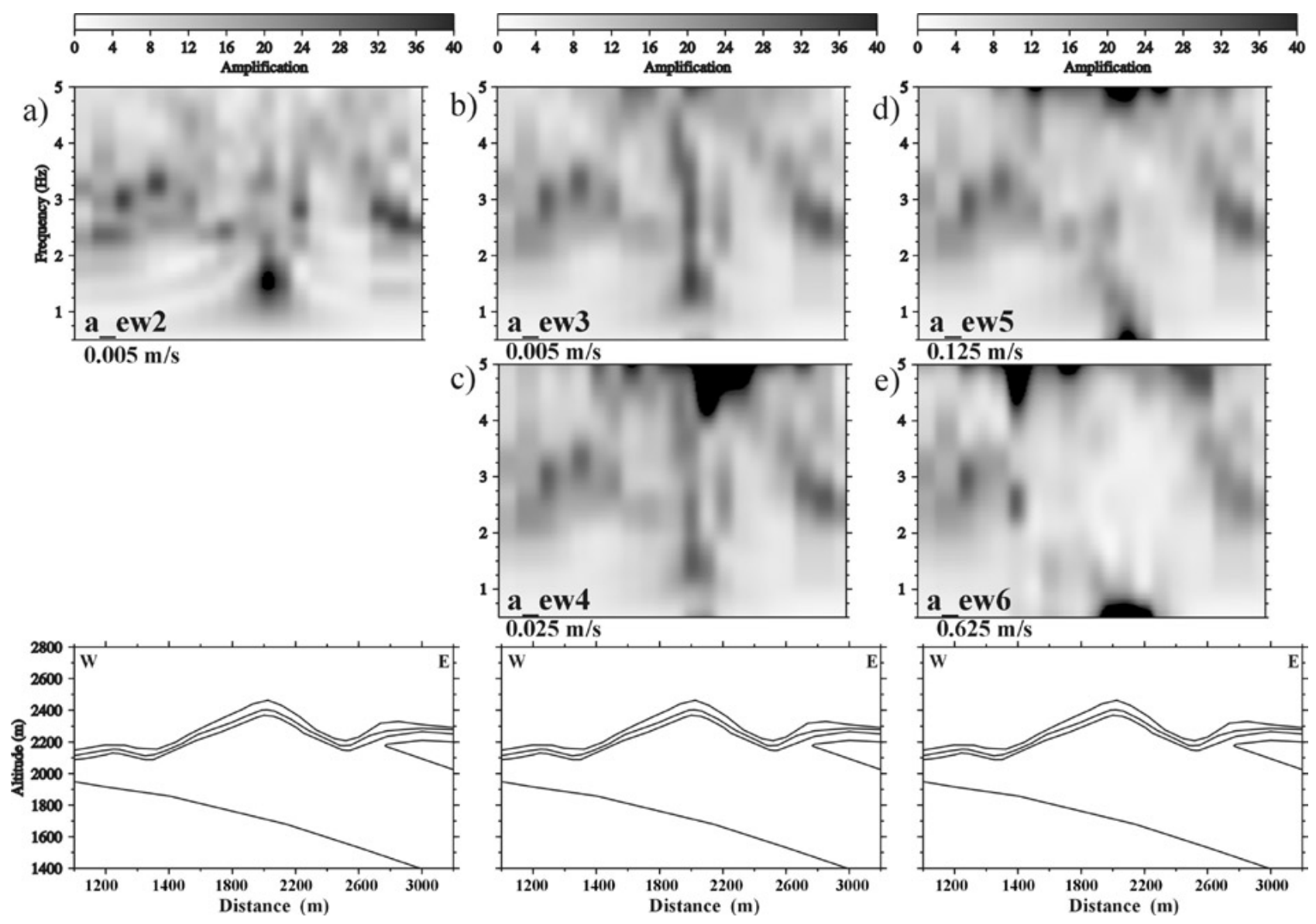

Fig. 8. The influence of deformation on the transfer function distributions over the elastic Ananevo E-W model without (a) and with contact slip (b) to (e) shown for the simulations a_ew2 (a), a_ew3 (b), a_ew4 (c), a_ew5 (d) and a_ew6 (e). See Table 3 for the modelling characteristics. The peak-amplitude of the seismic input is indicated for each run.

ling slope stability. In the preceding, it has been shown that it depends on the site geology and on the source amplitude and duration. In this regard, it was examined if the source frequency may also influence seismic slope movements. Therefore, simulations were run with sources composed of one $0.625 \mathrm{~m} / \mathrm{s} \mathrm{S}$-wave cycle characterized by three different frequency contents with a central frequency of respectively $2 \mathrm{~Hz}, 1 \mathrm{~Hz}$ and $4 \mathrm{~Hz}$. These inputs were applied to the same $30^{\circ}$-slope model including elastic layering, a regular block structure and additional fractures $\left(22^{\circ} \mathrm{dip}\right)$. The results are shown as $x$-displacement contour snapshots of the model obtained $10 \mathrm{~s}$ after initiation of the $2 \mathrm{~Hz}$ (Fig. 11a), $1 \mathrm{~Hz}$ (Fig. 11b) and $4 \mathrm{~Hz}$ (Fig. 11c) seismic source. It can be observed from these plots that the $1 \mathrm{~Hz}$ and $2 \mathrm{~Hz}$ sources produce similar displacements close to the surface. By looking at the maximum surface displacement values it can even be noticed that these are slightly larger in the case of the $2 \mathrm{~Hz}$ source $(0.8 \mathrm{~m}$ against $0.6 \mathrm{~m})$. However, the deformation induced by the $1 \mathrm{~Hz}$ source becomes relatively stronger at greater depth, whereas it almost disappears below the upper secondary joint in the case of the $4 \mathrm{~Hz}$ source. This indicates that a shaking produced by a source with a low source frequency, i.e. a large earthquake, is responsible for an increasing thickness of the deformed material. It needs, now, to be explained why the surficial deformation induced by the $2 \mathrm{~Hz}$ source is slightly larger than the one induced by the $1 \mathrm{~Hz}$ source. Therefore, the natural response should be taken into consideration. Indeed, modelling with the Ananevo N-S section (Fig. 6) revealed a fundamental frequency of exactly $2 \mathrm{~Hz}$ at the top of the slope. This implies that the shaking amplitudes and, hence, the surface displacements are maximum for the input with an energy content centered on this frequency of $2 \mathrm{~Hz}$.

In addition to the structural and seismic ground motion factors, also other slope stability factors were included in the simulations, such as lubrication (strongly reduced shear strength) along the potential sliding surfaces or groundwater pressures. Both played a major part in the simulation of very large deformations and prolonged sliding. The possible affect of groundwater pressure on such processes is shown with the following example. 
a)

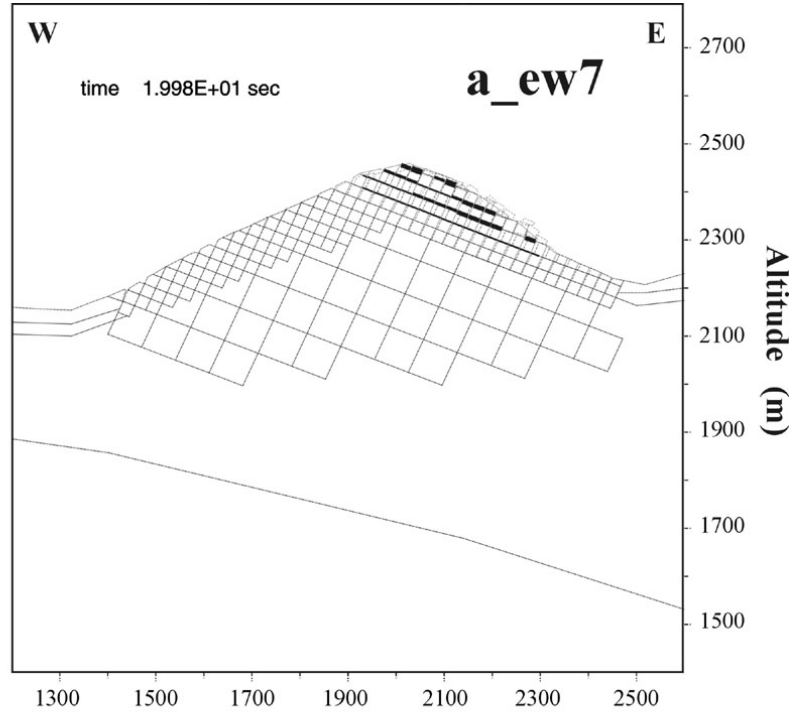

b)

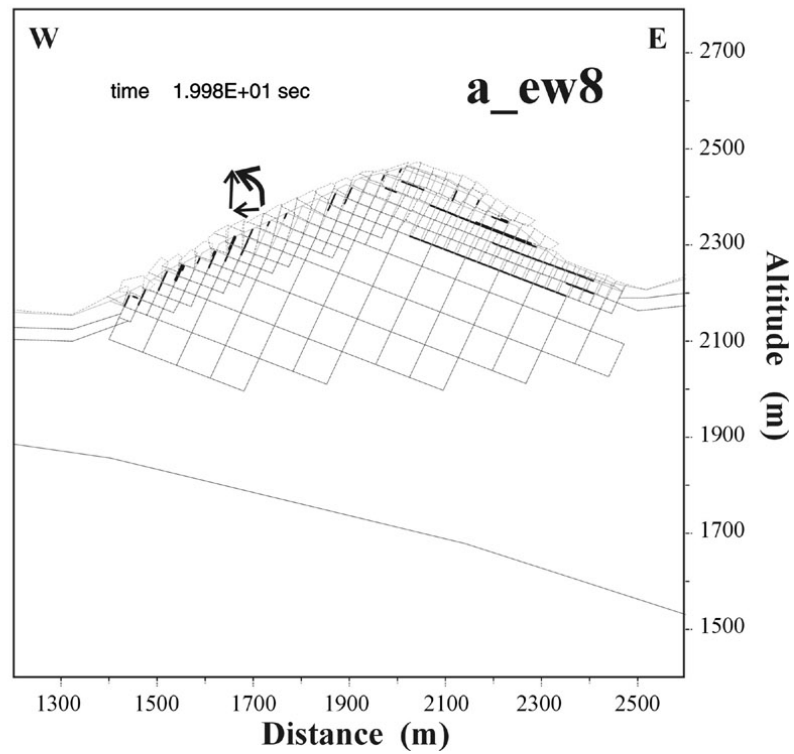

Fig. 9. Block deformation plots for the simulations a_ew7 (a) and a_ew8 (b) with the Ananevo E-W model composed of elastic and of plastic block material, respectively. Presented are the original block structure (thin grey lines) overlaid by the final block deformation 5-times amplified (thin black lines) and the shear displacement along joints (bold black lines, thickness marks the amount of displacement, with a maximum of $5 \mathrm{~m}$ shear displacement). See also arrows (in b) marking the displacements induced by the bending (bold arrow). The input is composed of twelve $2 \mathrm{~Hz}$ cycles with an amplitude of $0.625 \mathrm{~m} / \mathrm{s}$.

\subsubsection{The Suusamyr Landslide (NNW-SSE) section}

For the Ananevo site, dynamic modelling in the elastic domain could be compared with characteristics of recorded ground motions (Part A: Havenith et al., 2003), which guided further simulations of plastic deformation. Around the $\mathrm{Su}-$ usamyr landslide, no experimental ground motion data had been collected; the simulation results may therefore be con- sidered as "blind predictions". On the other hand, quite reliable information exists on the subsurface geology. Combined with data from geoelectric profiles, observations in two trenches in "stable" ground also allowed us to roughly determine depth of the groundwater level within the lower part of the arenite layer. The structural, lithological and hydrogeological information were then taken into account for the model designing. Special attention was paid to the relative influence of site effects and groundwater pressure on the seismic slope movements. Therefore, models were subjected to various hydrogeological conditions, which are not precisely known due to the changed morphology before failure.

The elasto-dynamic behaviour of the Chet-Korumdy ridge is characterized by an overall high amplification level due to the presence of surface layers, with highest values at low frequency in the crest region (Fig. $7 b$ ). In the plastic domain, groundwater revealed to be a crucial factor involved in slope stability. Deformation without groundwater flow is principally marked by a general sagging of the ridge, particular in the crest region (run suus 3 in Fig. 12a). Additional groundwater flow clearly triggers bedding failure within the upper arenite layer sliding over the silty clay layer (run suus 4 in Fig. 12b). What clearly distinguishes the simulation results with and without groundwater flow is the location of the upper slip surface inside the arenite layer: immediately south of the crest in the former and in the middle of the slope in the latter case. Also the amount of shear displacement is different, a few meters along the upper slip fractures in the dry model against more than forty metres along the sliding surface at mid-slope location in the groundwater flow model. These large displacements (Fig. 12b) are mainly produced after the propagation of four $0.625 \mathrm{~m} / \mathrm{s}$ cycles. Hence, the development of the landslide involves significant postseismic deformation. This appears, however, only under conditions of critical static slope stability $(F s \leq 1)$. Indeed, the groundwater level modelled in suus4 is slightly higher than in the equivalent model (suus5 in Table 3) with a $F s$ of 1.09 to 1.18 ), which implies a drop of the $F s$ down to about 1 . In the latter stable model, the slope stopped to move almost immediately after the last waves were propagated. With a groundwater level raised at the foot of the slope (like in suus4 in Fig. 12b), the arenite layer failed first in the lower part. Then, the arenite material failed in a higher position and slid downward (see arrow in Fig. 12b) and formed a slump delimited uphill by a clear scarp. For the simulation result shown in Fig. 12b, scarp and slump developed in a similar location as the actual Suusamyr debris slump, due to the higher groundwater level in the lower part of the slope. When the groundwater level was raised in a higher position, the slope failed over a larger area. Thus, location and size of the scarp are most sensitive with regard to the shape and depth of the groundwater level, which may be considered as crucial factors. From the simulations it may, therefore, be inferred that the mid-slope failure is likely (but not proved) to be connected with a higher groundwater level at the foot of the slope. Another or complementary explanation for the development of instability could be the reduction 

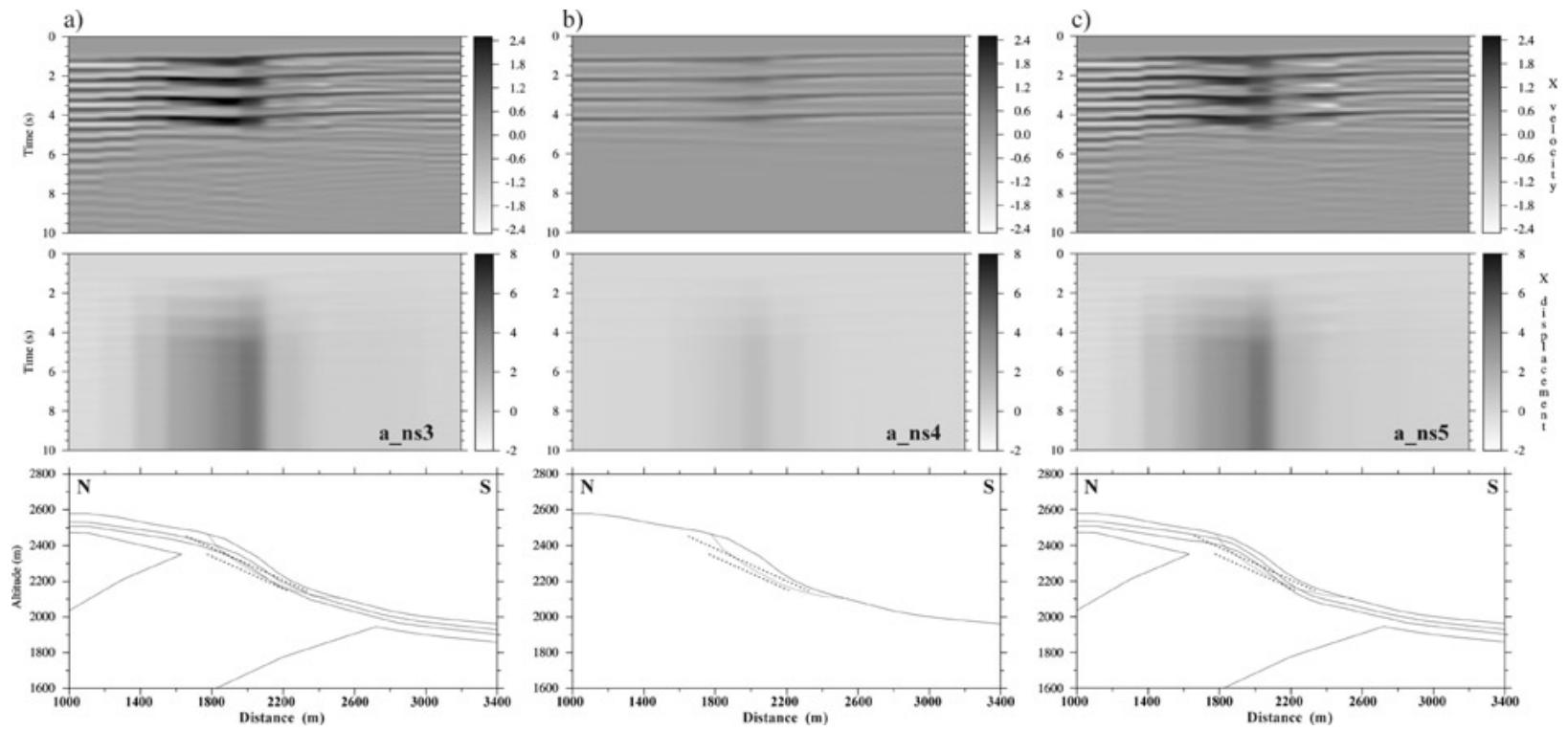

Fig. 10. Time histories of $x$-velocities $(\mathrm{m} / \mathrm{s})$ and $x$-displacements $(\mathrm{m})$ over the plastic Ananevo N-S block model with (a),(c) and without (b) elastic layering, with a steep slope, two joint sets and auxiliary fractures ( $25^{\circ}$ dip, short-dashed lines) are shown for the simulations a_ns 3 (a), a_ns4 (b) and a_ns5 (c). The input is composed of four $2 \mathrm{~Hz}$ cycles with an amplitude of $0.625 \mathrm{~m} / \mathrm{s}$.

of the shear strength along the sliding surface as it was simulated with other models. These results reveal that the Suusamyr landslide could only develop if the initial conditions were changed during deformation processes. However, they still cannot explain how this happened.

Besides the development of the landslide, also the formation of the graben at the top of the Chet Korumdy ridge (Fig. 4a) was analysed. It can be directly related to the simulated sagging of the Chet Korumdy ridge induced by strong shaking at the hilltop, even under dry conditions.

\subsection{Discussion on the deformation mechanisms}

The type of deformation mechanisms simulated with the Suusamyr and Ananevo models are obviously not the same. Along the southern slope of the Ananevo site, block tilting or plastic bending was commonly simulated (similar to the plot in Fig. 9b), while sagging systematically occurred along the crest and southern slope of the Chet Korumdy ridge. For the bending mechanism, two pre-conditions sine qua non can be inferred from the simulation results: the slope is composed of plastic (but not soft) material cut by steep contacts (dipping into or out of the slope). These conditions are, for example, verified for plastic rocks cut by steep joints or for intensively compacted and sub-vertically fractured sediments presenting a certain stiffness (rigidity). Strong shaking applied to mountain ridges or slopes gradually induces a permanent off-slope rotation of the steeply inclined rock (or rigid sediment) columns. The amount of the bending is larger over steeper slopes. For fixed material shear strength properties, a lowered shear strength along the steep joints also enhances bending. If the bulk shear strength is significantly lower (compare material cohesion and friction values for the Ananevo and the Suusamyr models in Tables 1 and 2), the bending of the slope material turns into a sagging, independently of the fabric. Such kind of behaviour applies to a soft sediment lithology, where the material is sheared and slips along a potential sliding surface, such as a layer interface. If pre-existing weakly dipping fractures intersecting the slope surface allow the material to slide downward, sagging can also be observed along slopes composed of rigid materials (plastic or rigid rocks in Fig. 9 or stiff sediments).

The plastic deformation associated with bending or sagging cannot result in the development of a landslide as long as a sliding surface has not formed. In the case of the sagging, the initiation of a failure surface can be conceptualised as a simple enhancement of shearing within the soft material (due to shear strength reduction or increased groundwater pressures). The initiation of a sliding surface through rock or stiff sediments cut by steeply dipping joints seems more complex since the pre-existing fabric is not favourable for downward movements. However, it is known from static slope failures initiated under comparable structural conditions that sliding surfaces can also originate from bending. Indeed, the bending of rock columns induces rising tensile stresses where the curvature is strongest (Sjöberg, 1999). If these stresses trespass the shear strength of the rocks, the rock columns break. The summation of ruptures through adjacent rock columns gradually results in the formation of a base failure surface. These transformation processes imply the rupturing of initially (almost) continuous material, which could not be simulated with the applied tools. In consequence, the simulations only considered the result of breaking (i.e. the potential sliding surface). 
a)

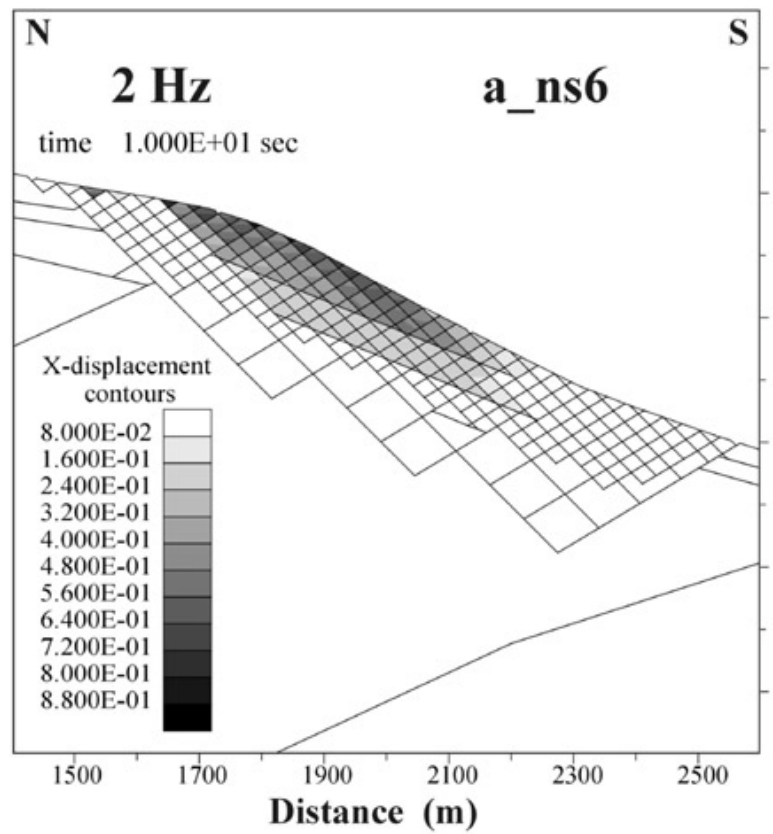

b)

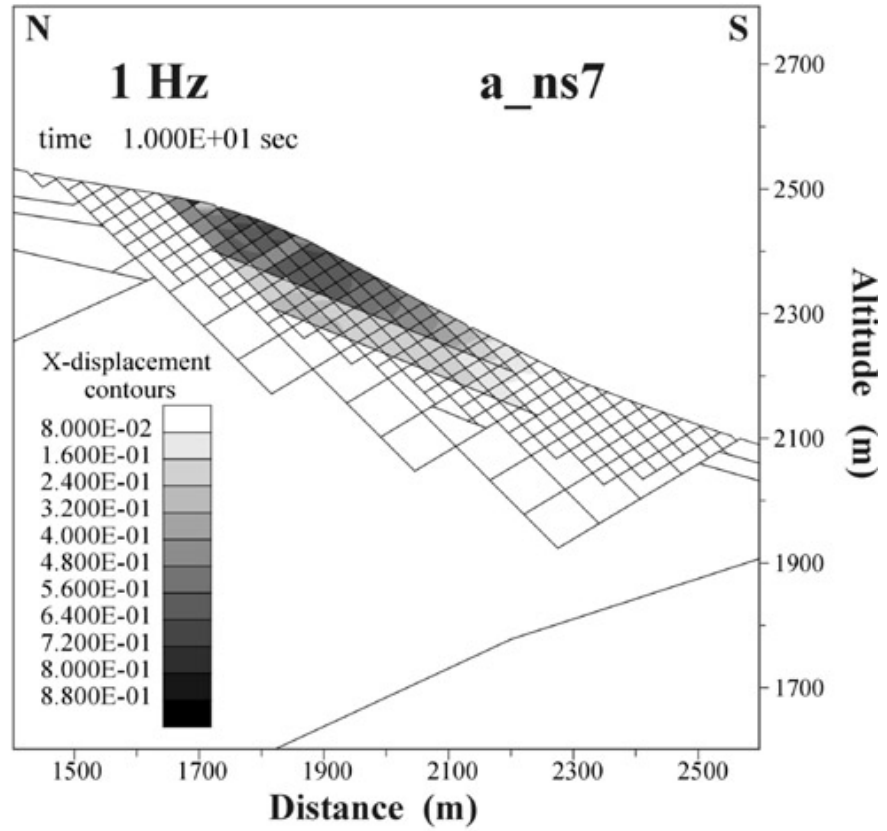

c)

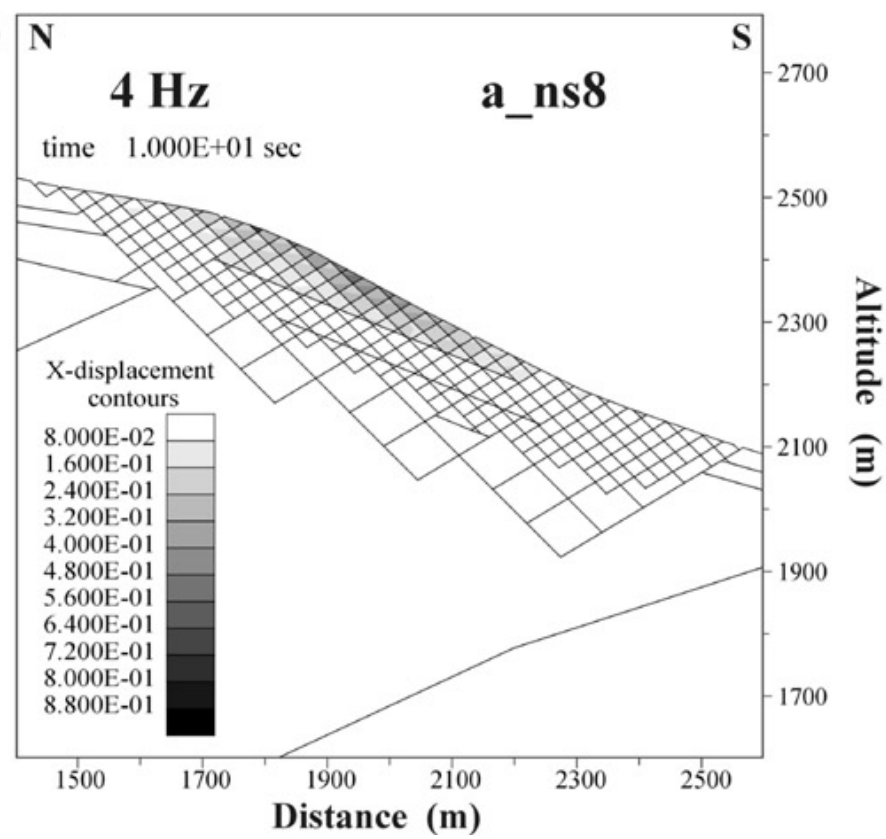

Fig. 11. $X$-displacement contour snapshots of the elastic Ananevo N-S block model with a $30^{\circ}$-slope, two joint sets and $22^{\circ}$ dipping auxiliary joints computed $10 \mathrm{~s}$ after initiation of a $0.625 \mathrm{~m} / \mathrm{s} \mathrm{S}$-wave source of $2 \mathrm{~Hz}$ (a_ns6, (a), $1 \mathrm{~Hz}$ (a_ns7, (b) and $4 \mathrm{~Hz}$ (a_ns8, (c).

\section{Conclusions}

This paper presented aspects of a numerical study of two earthquake-triggered landslides, the Ananevo rockslide and the Suusamyr debris slump-flow, located in Kyrgyzstan, in the Northern Tien Shan Mountains. Based on manifold field data collected at these sites, geological observations and geophysical measurements (see Part A: Havenith et al., 2003), several types of distinct element models have been built. In order to analyse the influence of geological and seismic factors on slope failures, simulations were performed using the UDEC software.

An initial estimate of the impact of geological components on slope stability was made under static conditions. This permitted static factors of safety have to be determined for several basic models. The computations revealed a very high stability of the Ananevo rock slope and a factor of safety only slightly larger than 1 for the Suusamyr site. 


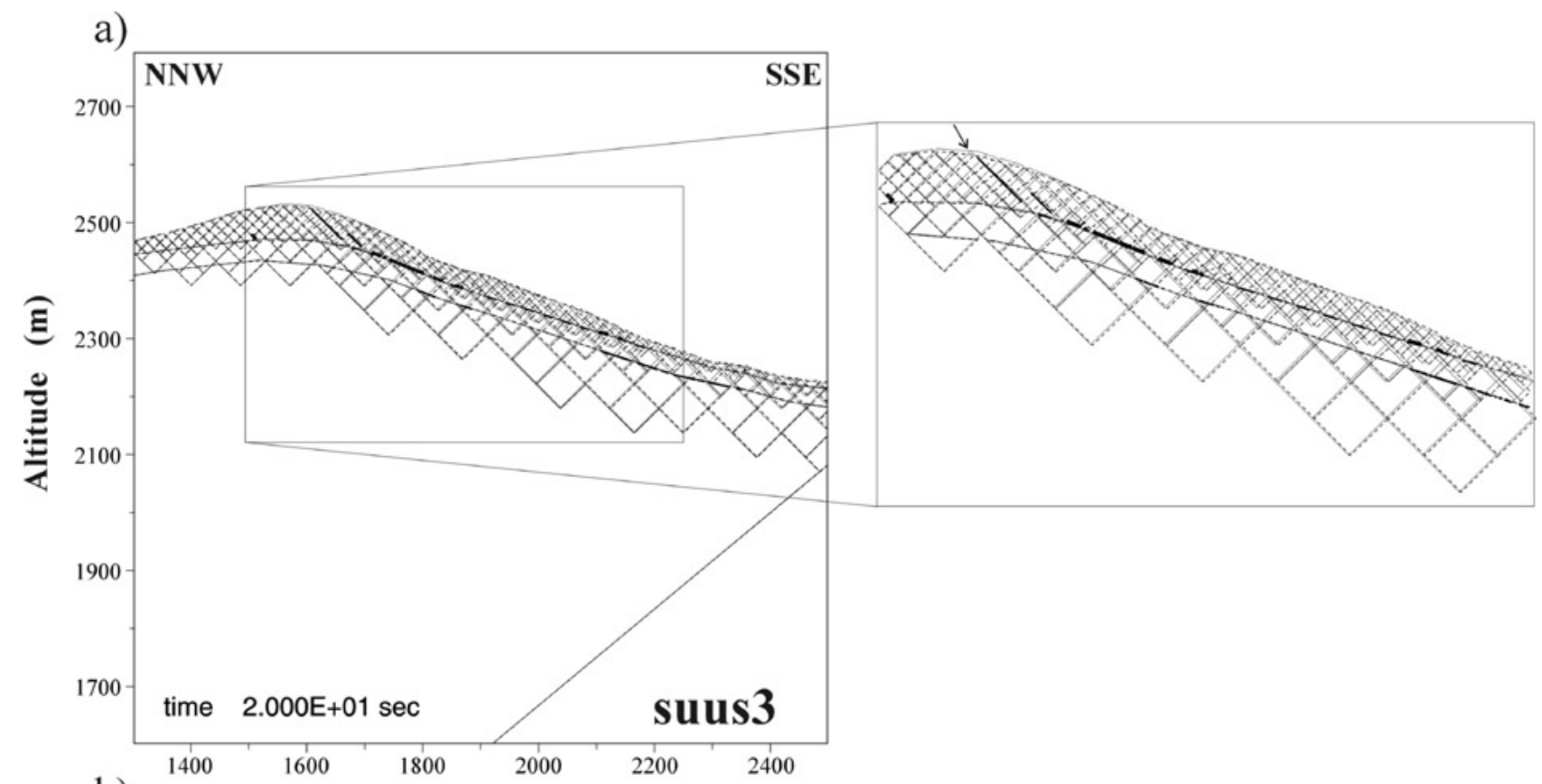

b)

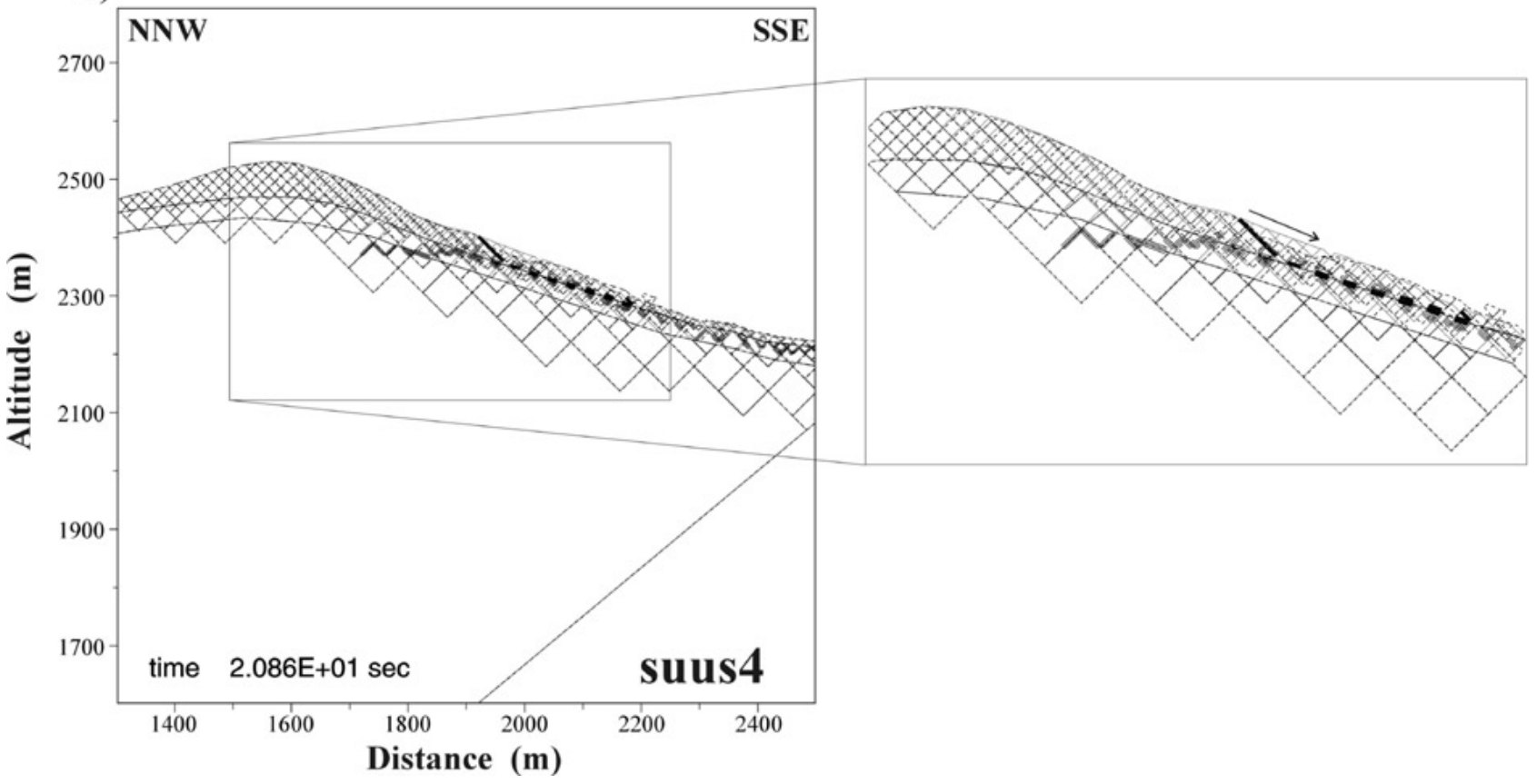

Fig. 12. Block deformation and local zoom (see also arrow indicating the main sliding motion) of the plastic Suusamyr block model without (a) and with (b) groundwater flow shown for the simulations suus 3 and suus4. The input is composed of twelve (a) and four (b) $0.625 \mathrm{~m} / \mathrm{s}$ S-wave cycles. Plotted are the original block structure (thin grey lines) overlaid by the final block deformation (thin dashed black lines), the shear displacement along joints (bold black lines, maximum thickness for a $10 \mathrm{~m}$ (a) and a $50 \mathrm{~m}$ (b) shear displacement) and groundwater level (bold grey lines in b).

Secondly, earthquake dynamics were modelled in the elastic domain and validated through comparisons with analogue results obtained previously with the AHNSE code (known to be a reliable tool in simulating seismic ground motions). Both types of simulations predicted strongest amplification at the mountain crest in the low frequency domain. This characteristic compares well with the ground motion data recorded at the site.
From the results of the dynamic simulations, it can be concluded that such site effects also enhance plastic deformation processes. On the Ananevo rock slope, ground motion amplification leads to stronger bending of rock colons and hence to higher shear stresses within the material. In the case of the Chet-Korumdy ridge composed of soft sediments, initial deformation was mainly related to sagging of the low shear strength material (formation of the graben at the top of 
the ridge). Further movements due to bedding failure were exclusively produced in connection with groundwater flow (slumping along the slope).

In general terms, the influence of the local conditions on seismic slope stability can be summarized thus:

- surface layer amplification clearly contributes to larger permanent co-seismic deformation, whether or not groundwater pressures are involved;

- largest surface deformation occurs for source frequencies in the range of the fundamental frequency of the site; in addition, lower frequencies are likely to induce deformation over a greater thickness of the subsurface material;

- co-seismic deformation is further enhanced by plastic material behaviour;

- significant downward motion implies the development of a sliding surface;

- large post-seismic displacements depend on lowering of the static slope stability factor by the reduction of the effective stresses due to increasing groundwater pressures and/or by the reduction of shear strength along the sliding surface.

The three first points reveal the strong affect of the surface morphology and surficial layering (depth of weathered rocks or of sediment cover) on co-seismic movements. They also allow us to define the particularity of seismically triggered landslides with regard to mass movements developed under static conditions. It has been shown that the amount of plastic bending and sagging deformation correlates well with the amplitude of shaking and, hence, with local amplification effects. Consequently, the initiation of the sliding surface connected with these deformation processes also depends on site effects. In particular, convex topographies covered by surficial low-velocity layers proved to be particularly prone to these effects. Such conditions occur most often along ridges and at the top of slopes. The sliding surface is therefore most likely to initiate at these points and to propagate downward. This is supported by the extensive field evidence of incipient seismic landslides (Harp et al., 1981; Durville and Méneroud, 1982 among others) located higher on the slopes with decreasing deformation downhill. In this respect, seismically triggered slope failures clearly differ from static slope failures that commonly initiate at the bottom of the slope (Sjöberg, 1999). For the two examples presented here, such a type of initiation must be assumed, as later landslide processes have completely erased earlier deformation stages. However, the high location of the Ananevo rockslide scarp, the formation of a graben along the Chet Korumdy ridge, and the presence of very low velocity layers at both sites, indicate that large site effects most probably contributed in triggering the failures.

For regional seismic landslide hazard assessment carried out on a GIS platform, this study implies that not only slope angle, material shear strength and groundwater level maps should be combined with seismic hazard maps, but also the distribution of surface convexity and of the dynamic elastic properties of the subsurface materials. As a result, the studies are likely to better predict the spatial variability of the seismic response and the related susceptibility to failure. However, the assessment should not only include estimates of possible future seismic landslide locations, but also of landslide sizes and run outs, the major risk factors. Therefore, the link between the type of the earthquake source and the site conditions needs to be better understood both from field evidence (size-frequency relationships) and modelling.

Acknowledgements. The research leading to this article was funded by the European Community (EC, DG XII contract IC15-CT970202) and by the Fonds National de la Recherche Scientifique of Belgium. We wish to thank the KIS and GEOPRIBOR teams, students and scientists, who helped in acquiring the geophysical data.

\section{References}

Ambraseys, N. and Srbulov, M.: Earthquake induced displacements of slopes, Soil Dyn. Earthqu. Eng., 14, 59-71, 1995.

Bathe, K.-J. and Wilson, E. L.: Numerical Methods in Finite Element Analysis, New Jersey, Prentice-Hall, 1976.

Benko, B. and Stead, D.: The Frank slide: a reexamination of the failure mechanism, Can. Geotech. J., 35, 299-311, 1998.

Boore, D. M.: SMSIM-Fortran programs for simulating ground motions from earthquakes: version 1.0, U.S. Geol. Surv., Open-File Report 96-80-A, 1996.

Calvetti, F., Crosta, G., and Tatarella, M.: Numerical simulation of dry granular flows: from the reproduction of small-scale experiments to the prediction of rock avalanches, Rivista Italiana Geotecnica., XXXIV (2), 21-38, 2000.

Cundall, P. A.: A computer model for simulating progressive, largescale movements in blocky rock systems, in Proc. Symp. Int. Soc. Rock Mechanics, Nancy, France, 1971.

Cundall, P. A.: UDEC-A Generalized Distinct Element Program for Modelling Jointed Rock, Peter Cundall Associates, Report PCAR-1-80; European Research Office, U.S.Army, Contract DAJA37-79-C-0548, March, 1980.

Damjanac, B., Detournay, E., and Huang, H.: Effects of underground nuclear tests in French Polynesia on the stability of Atoll flanks, FLAC and Numerical modelling in geomechanics, edited by Detournay and Hart, 23-31, 1999.

Dawson, E. M. and Roth, W. H.: Slope stability analysis with FLAC, FLAC and Numerical modelling in geomechanics, edited by Detournay and Hart, 3-9, 1999.

Durville, J.-L. and Méneroud, J.-P.: Phénomènes géomorphologiques induits par le séisme d'El Asnam, Algérie. Comparaison avec le séisme de Campanie, Italie, Bull. liaison. Labo. P. et Ch., 120, 13-23, 1982.

Faccioli, E., Maggio, F., Paolucci, R., and Quarteroni, A.: 2-D and 3 -D elastic wave propagation by a pseudo-spectral domain decomposition method, J. Seism., 1, 237-251, 1997.

Forlati, F., Gioda, G., and Scavia, C.: Finite element analysis of a deep-seated slope deformation. Rock Mech. Rock Engineering, 34, 135-159, 2001.

Harp, E. L., Wilson, R. C., and Wieczorec, G. F.: Landslides from the February 4, 1976, Guatemala earthquake. The Guatemala 
earthquake of February 4, 1976, Geol. Surv. Prof. Paper 1204A, 1-35, 1981.

Havenith, H. B., Jongmans, D., Abdrakhmatov, K., Trefois, P., Delvaux, D., and Torgoev, I. A.: Geophysical investigation of seismically induced surface effects: case study of a landslide in the Suusamyr valley, Kyrgyzstan, Surv. in Geoph., 21, 349-369, 2000.

Havenith, H.-B., Strom, A., Jongmans, D., Abdrakhmatov, K., Delvaux, D., and Trefois, P.: Seismic triggering of landslides, Part A: Field evidence from the Northern Tien Shan, Nat. Haz. Ear. Sys. Sci., 3, 135-149, 2003.

Hoek, E. and Bray, J.: Rock slope engineering, Institution of Mining and Metallurgy, 1981.

Ishihara, K., Haeri, S., Moinfar, A., Towhata, I., and Tsujino, S.: Geotechnical aspects of the June 20, 1990 Manjil earthquake in Iran, Soils and Foundations, 32(3), 61-78, 1992.

Itasca Consulting Group: UDEC User's manual, 1991.

Janbu, N.: Slope stability computations - Embankment - Dam Engineering, Casagrande Volume, Wiley, New York, 1973.
Kramer, S. L. and Smith, M. W.: Modified Newmark model for seismic displacements of compliant slopes, J. of Geotech. and Geoenv. Eng., 123, 635-644, 1997.

Newmark, N.: Effects of earthquakes on dams and embankments, Géotechnique, 15, 137-160, 1965.

Paolucci, R., Faccioli, E., and Maggio, F.: 3-D response analysis of an instrumented hill Matsuzaki, Japan, by a spectral method, J. Seism., 3, 191-209, 1999.

Philipponnat, G.: Fondations et ouvrages en terre, edited by Eyrolles, 1979.

Sjöberg, J.: Analysis of failure mechanisms in high rock slopes, in: Proc. 9th Congr. on Rock Mech., edited by Vouille and Berest, 127-130, 1999.

Ugai, K., Wakai, A., and Ida, H.: Static and dynamic analyses of slopes by the 3-D elasto-plastic FEM, in: Proc. Landslides, edited by Senneset, 1413-1416, 1996.

Zienkiewicz, O. C., Humpheson, C., and Lewis, R. W.: Associated and non-associated visco-plasticity and plasticity in soil mechanics, Géotechnique 25, 671-689, 1975. 